\title{
An Update on the Ophthalmologic Features in the Phakomatoses
}

\author{
Solmaz Abdolrahimzadeh,, ${ }^{1}$ Andrea Maria Plateroti, ${ }^{1}$ \\ Santi Maria Recupero, ${ }^{2}$ and Alessandro Lambiase ${ }^{1}$ \\ ${ }^{1}$ Ophthalmology Unit, DAI Testa/Collo, Azienda Policlinico Umberto I, Department of Sense Organs, \\ University of Rome "Sapienza", Viale del Policlinico 155, 00161 Rome, Italy \\ ${ }^{2}$ Ophthalmology Unit, St. Andrea Hospital, NESMOS Department, University of Rome "Sapienza", \\ Via di Grottarossa 1035-1039, 00189 Rome, Italy \\ Correspondence should be addressed to Solmaz Abdolrahimzadeh; solmazzadeh@gmail.com
}

Received 18 December 2015; Revised 11 May 2016; Accepted 6 June 2016

Academic Editor: Lawrence S. Morse

Copyright (C) 2016 Solmaz Abdolrahimzadeh et al. This is an open access article distributed under the Creative Commons Attribution License, which permits unrestricted use, distribution, and reproduction in any medium, provided the original work is properly cited.

\begin{abstract}
Neurofibromatosis type 1, tuberous sclerosis complex, and Von Hippel-Lindau disease, historically classified as the phakomatoses, are hereditary multisystem disorders characterized by the presence of hamartoma, which carry the risk of malignant transformation. The alteration of tumor suppressor genes seems to be at the basis of their pathophysiogenetic mechanism. Lisch and choroidal nodules in neurofibromatosis type 1, retinal astrocytomas in tuberous sclerosis complex, and retinal capillary hemangioma in Von Hippel-Lindau disease are the principal ophthalmic hamartomatous manifestations. The advent of novel imaging techniques such as near infrared reflectance and optical coherence tomography has provided unprecedented insight on the choroidal and retinal features of these diseases. These methods have improved early diagnosis and the ongoing surveillance in these conditions. Among an array of treatment modalities, antivascular endothelial growth factor therapy has been used in the management of retinal hamartomas but results have been varied. This review is an update on the pathophysiogenetic mechanisms, ophthalmic manifestations, and novel treatment strategies in the phakomatoses with emphasis on the role of imaging techniques.
\end{abstract}

\section{Introduction}

Van der Hoeve in 1932 included neurofibromatosis type 1 (NF1), tuberous sclerosis complex (TSC), and Von HippelLindau disease (VHL) in a group named "phakomatoses." The conditions were defined as hereditary multisystem disorders, which share the common characteristics of the presence of "spots, tumefactions, and cysts" which were described as "phakomata" (from the Greek term "phakos" for motherspot), which proliferate and carry the risk of malignant transformation [1]. Over the years there has been much debate and some authors have suggested the inclusion of other ophthalmic diseases with neurocutaneous manifestations in the group of phakomatoses [2-6], but advances in molecular genetics provide evidence of the role of tumor suppressor genes in the pathophysiogenetic mechanisms of NF1, TSC, and VHL disease, which all have a familial pattern of inheritance, variable expressivity, and multisystem tumors with a risk of malignant transformation and can be considered the "true phakomatoses" [7-9].

Recent progress in multimodal imaging techniques, like near infrared reflectance (NIR) and optical coherence tomography (OCT), has enhanced our knowledge on the retinal manifestations of these diseases, providing unprecedented information on the morphological aspects of hamartomas. These methods have improved early diagnosis and the ongoing surveillance in these conditions. Indeed, facilitated and noninvasive imaging with NIR has led to propose choroidal nodules as an additional diagnostic criterion in NF1, which aids diagnosis in children and in uncertain cases [10]. Peripapillary retinal nerve fiber layer imaging with OCT is potentially a rapid tool for monitoring children with NF1 as regarding optic pathway glioma [11]. Furthermore, OCT has been used to better classify retinal alterations in TSC [12]. Novel therapeutic strategies involve the tentative use of antivascular endothelial growth factors (anti-VEGF) in 
the management of hamartomas and/or the complications arising from their presence.

The present paper is a detailed review of the ophthalmological features in the phakomatoses with particular attention to novel imaging findings and ongoing management methods.

\section{Neurofibromatosis Type I}

NF1 is an autosomal dominant disease due to deletions or mutations of the neurofibromin gene located on chromosome 17p11.2 [13]. The prevalence of the disease is about $1: 3000$ and is not based on gender, race, ethnic group, and geographical area [14]. NF1 has complete penetrance and variable expressivity but in about $50 \%$ of individuals the condition is due to de novo (spontaneous) mutations [15-19].

Ophthalmological features included in the NIH diagnostic criteria of NF1 are Lisch nodules and optic pathway gliomas (OPG) [16]. Other ocular structures involved include the orbit, eyelid, conjunctiva, cornea, anterior chamber, ciliary body, and retina. In patients with absence of the greater wing of the sphenoid bone, the most dramatic clinical sign is a pulsating proptosis, which is synchronous with heartbeat. Other signs linked to dysplasia can be microphthalmus and enophthalmos [20]. Upper eyelid plexiform neurofibromas are unilateral and are observed in the first two years of life. They can increase in dimensions leading to asymmetrical ptosis with the typical freeboard "italic S" course of the eyelid margin. In some cases, enlargement can lead to elephantiasis and extend to the temporal and frontal areas creating facial asymmetry. Although various surgical approaches have been attempted, results are disappointing because of copious intraoperative bleeding and tendency to relapse [6, 20-22]. Sporadic conjunctival neurofibromas and typical asymptomatic hypertrophia of intrastromal corneal nerves (observed in one out of four patients) have been reported [6]. Corneal nerve thickening can possibly be due to the intrinsic genetic alteration of the disease with axon and Schwann cell abundance [23]. Similar to other genetic diseases with corneal nerve thickening, epithelial changes may result from possible corneal nerve dysfunction and should be evaluated when considering refractive corneal surgery in these patients $[24,25]$.

Lisch nodules of the iris represent the main ocular manifestation of NF1. They usually appear from the age of 2 years onwards and approximately $50 \%$ of children present nodules; by adulthood this number increases to over $90 \%$ [26-29]. The number of Lisch nodules is correlated with choroidal nodules [30] and we found that Lisch nodules are positively correlated with cutaneous neurofibromas with increasing age [27]. Lisch nodules are often pigmented and their color may vary from creamy white in dark irides to brown in blue and green irides. We observed that they can vary from dome-shaped nodules to masses with ragged borders and various grades of confluency (Figure 1) [27].

Ragge et al. reported that they were more frequently localized in the inferior hemifield due to the sunlight-shielding effects of the upper eyelid [28]; however, in our study we did

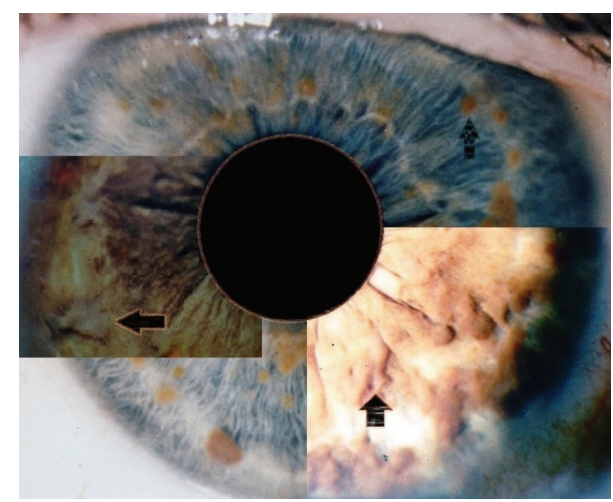

FIgURE 1: Morphological presentations of Lisch nodules. The upper and background image shows some shaped choroidal nodules. The image on the left shows nodules with ragged borders. The image on the right shows nodules with confluency (black arrows indicate Lisch nodules).

not find a predilection for any specific area [27]. Lisch nodules are easily observed with slit lamp examination; however, they can be difficult to detect due to poor cooperation of young patients, when they are small or flat, or when they are localized in the iris crypts [31] (Figure 2). Lisch nodules should not be confused with iris mammillations found in ocular melanosis which are smooth and homogenously distributed iris nodules that are commonly unilateral [32, 33].

Glaucoma onset is rarely seen in NF1, although multiple pathogenic mechanisms related to angle closure have been proposed. The most commonly reported mechanisms are infiltration of the anterior chamber by neurofibromas that obstruct the angle, secondary angle closure by neurofibromatous cysts or increased thickness of the ciliary body and choroid, neovascular glaucoma, and developmental angle abnormalities [34-36]. Optical coherence tomography of the anterior chamber and ultrasound biomicroscopy can show Lisch nodules and abnormalities of the ciliary body and chamber angle involved in glaucoma onset [37-39]. Morales et al. found ipsilateral glaucoma and increased axial length in $23 \%$ of 95 patients with orbitofacial involvement and associated findings were pigmentary patches or anterior synechia and thickening of the ciliary body [40]. Therefore, tonometry and visual field analysis in patients with NF1 is advisable although this is not always easy to perform in younger patients [41-44].

Choroidal abnormalities of NF1 are often difficult to detect via fundus biomicroscopic examination and fluorescein angiography (Figure 3 ).

Indocyanine green angiography in NF1 patients shows delayed perfusion of the choriocapillaris in areas corresponding to choroidal nodules $[45,46]$. Yasunari et al. used infrared monochromatic light to show multiple bright patchy choroidal alterations corresponding to choroidal nodules of the posterior pole in 33 eyes of 17 patients with NF1 [46]. Recently, Viola et al. evaluated choroidal alterations in NF1 patients using near infrared reflectance (NIR) in 190 eyes and found nodules in $82 \%$ of patients. They established a cut-off value of 1.5 nodules to make a diagnosis and 

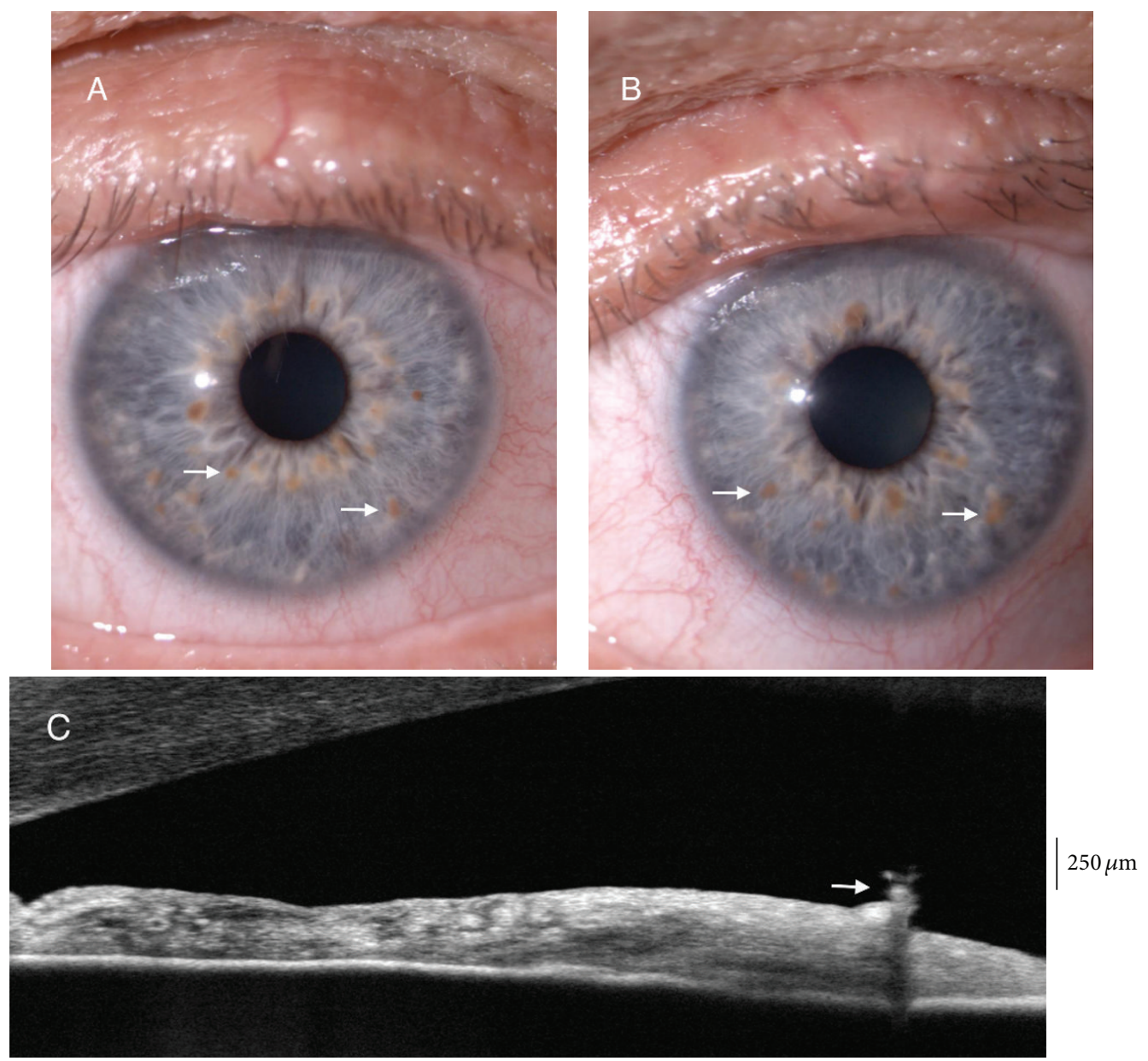

Figure 2: Lisch nodules in neurofibromatosis type 1. Slit lamp (A, B) and anterior segment optical coherence tomography images (C), arrows indicate Lisch nodules.

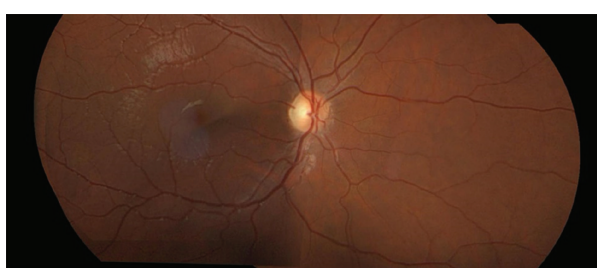

(a)

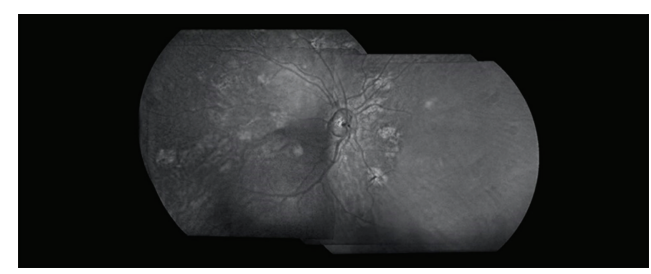

(b)

FIGURE 3: Color fundus photograph (a) and near infrared reflectance fundus image (b) in a patient with NF1. Patchy and rounded choroidal alterations are most apparent on infrared reflectance images.

proposed to include choroidal nodules among the diagnostic criteria [47] (Figure 4). NIR imaging with OCT to detect choroidal alterations has widened the armamentarium of ophthalmologists in the diagnostic process in NF1. OCT instrumentation is a valuable adjunct in the examination of children who cannot collaborate due to their young age and condition [10].

The enhanced depth imaging function of spectral domain OCT allows the visualization of deeper ocular structures than traditional OCT as the peak sensitivity is placed behind the retinal pigment epithelium [48]. Ayata et al. performed both longitudinal (B-scan) and transverse (C-scan) OCT imaging and observed choroidal nodules at different depths in the choroid and demonstrated that the overlying retina showed changes in thickness [49]. Rao and Choudhry found that the choroid over nodules had a loss of lucency suggesting vascular compression [50]. We previously reported on choroidal nodules in 38 eyes of 19 patients with NIR imaging and crosssectional EDI-OCT images and showed that NIR detected choroidal alterations corresponded to two types of hyperreflective choroidal nodules on EDI-OCT. Well-delineated, bright, rounded shape alterations on NIR corresponded to 

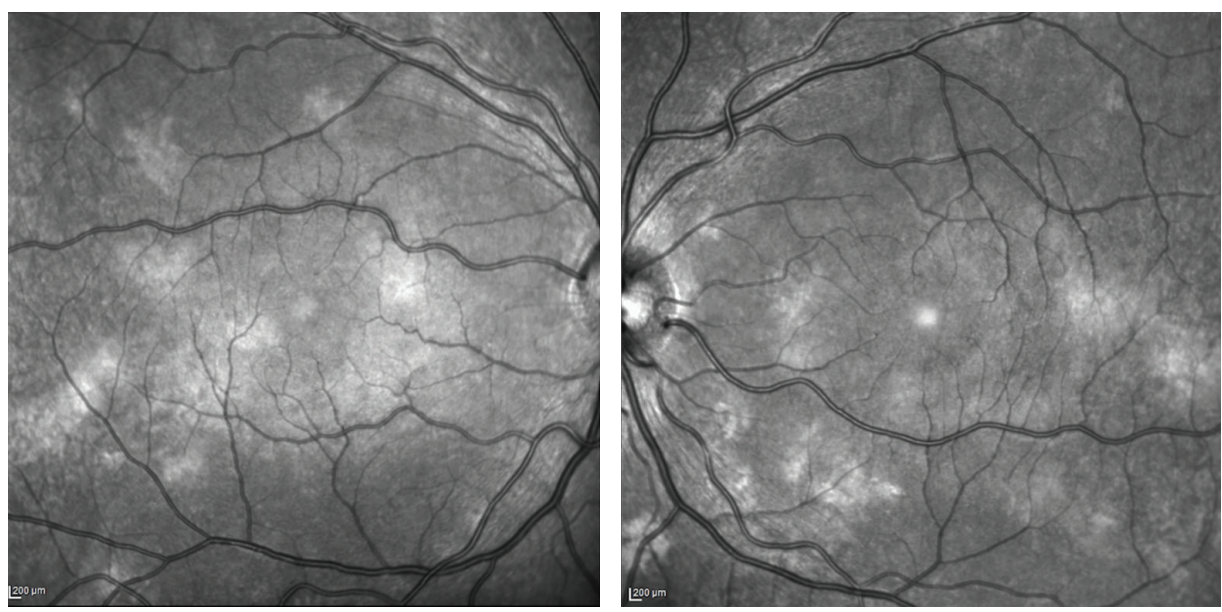

FIGURE 4: Near infrared reflectance showing choroidal alterations in neurofibromatosis type 1 . The typical rounded or patchy alterations are clearly shown.

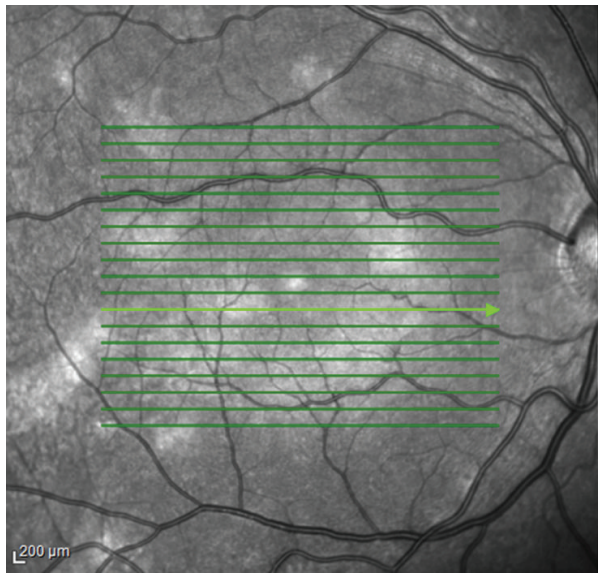

(a)

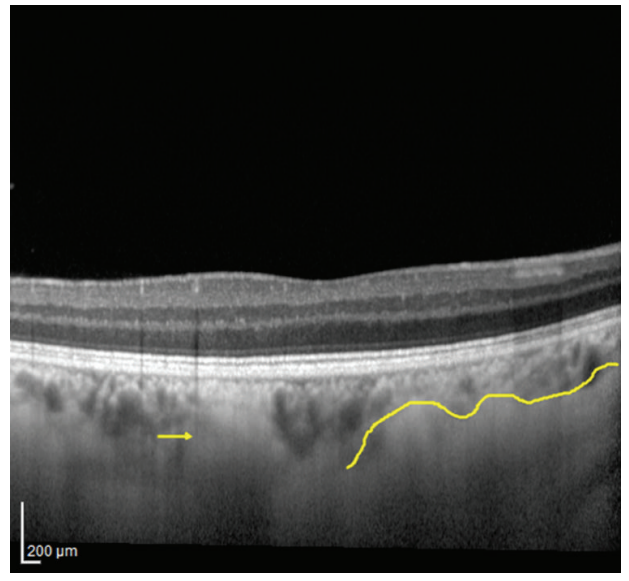

(b)

FIGURE 5: Raster (a) and corresponding cross-sectional (b) enhanced depth spectral domain optical coherence image of choroidal nodules in neurofibromatosis type 1 . The delineated area shows a laterally extending placoid type choroidal nodule whereas the arrow indicates a dome-shaped nodule.

"dome-shaped" hyperreflective formations on OCT-EDI and poorly defined patchy alterations corresponded to rather flat, irregularly shaped, hyperreflective "placoid" formations [26] (Figure 5).

Moreover, through manual segmentation measurements of retinal layer and choroidal thickness using OCT software, we demonstrated generalized choroidal and retinal thinning in patients with NF1 [26]. We showed that choroidal vasculature above nodules was altered in NF1 (Figure 6) and as the choroidal vasculature is the main vascular support for the outer retina, we hypothesized that compromised choroidal blood flow can lead to an alteration of retinal trophism [26].

Retinal microvascular anomalies consisting in small (second or third order venule) tributaries of the inferior or superior-temporal vein denominated "corkscrew retinal vessels," "hemangioma-like," or "ball of thread" retinal microvessels have been reported and these seem to be overlying areas corresponding to choroidal nodules as shown by NIR imaging (Figure 7 ) $[51,52]$.

Other retinal alterations such as multiple retinal capillary hemangiomas, astrocytic hamartomas, and, rarely, combined hamartomas of the retina and the retinal pigment epithelium (CHRRPE) were described [53]. OCT features of CHRRPE have been reported to include preretinal membranes, retinal striae, and a disorganization of the retinal layers including the retinal pigment epithelium and photoreceptors-ellipsoid zone $[54,55]$.

Optic pathway gliomas (OPG) have the most dramatic impact on visual acuity in NF1 patients. They are present in $15 \%-20 \%$ of children with NF1 before the age of eight [56]. These tumors are mainly grade I glial neoplasms, termed pilocytic astrocytomas, which are histologically similar to gliomas that arise sporadically in individuals without NF1 [56]. Although many OPGs are asymptomatic, one-third 


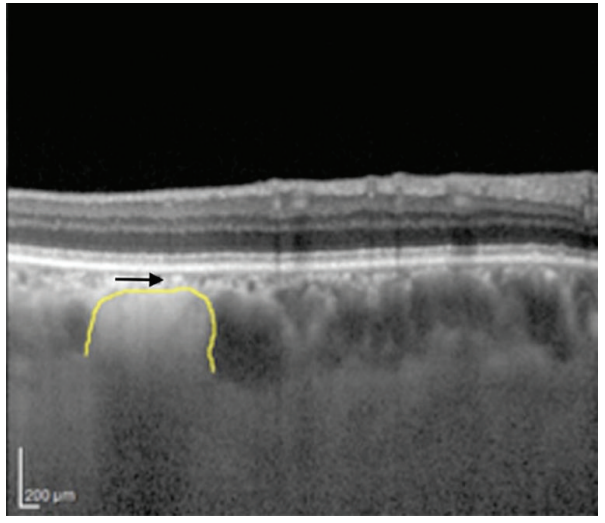

(a)

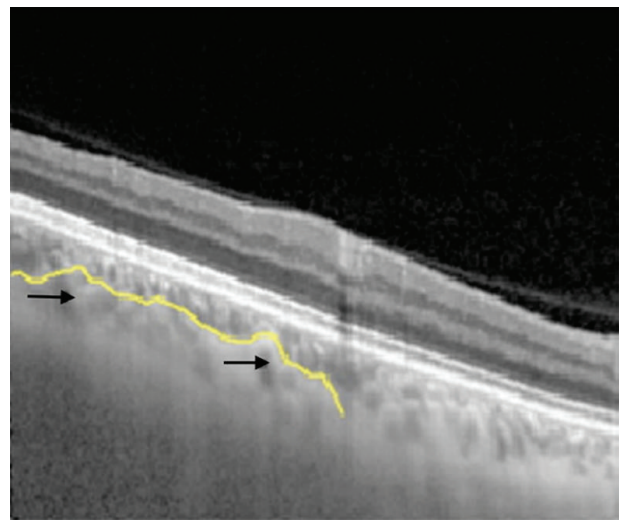

(b)

FIGURE 6: Optical coherence tomography-enhanced depth imaging of choroidal nodules and overlying choroidal vasculature features. (a) Delineated dome-shaped nodule; note the compressed appearance of choroidal vasculature and the absence of large caliber vessels. (b) Delineated placoid nodule; note the random localization of large caliber vessels among the irregular propagations of the placoid nodule (from [26]).

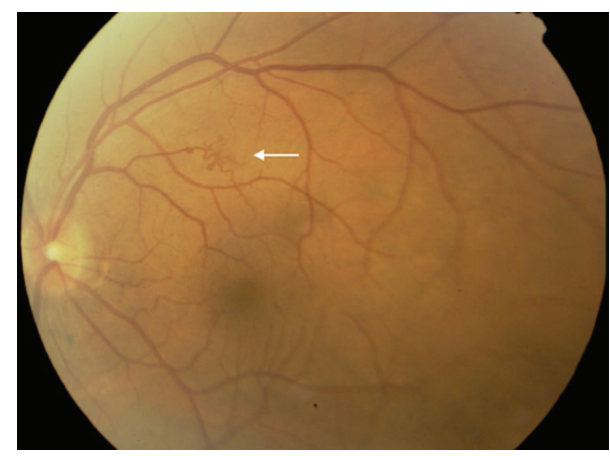

(a)

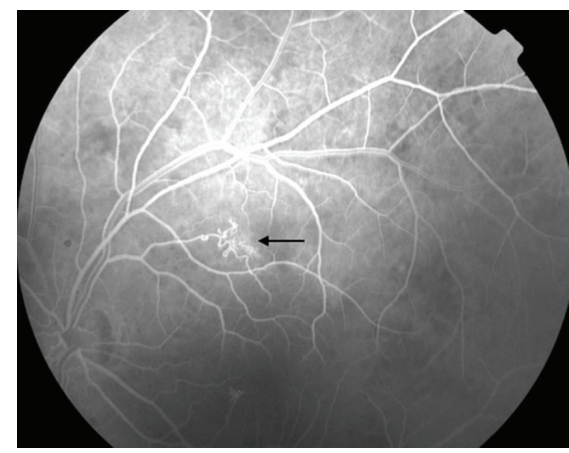

(b)

FIGURE 7: Retinal microvascular abnormality with "hemangioma-like" or "ball of thread" appearance in NF1. The retinal microvascular abnormality is shown with an arrow on the (a) fundus photograph and on the (b) fluorescein angiography image (modified from [52]).

to one-half can cause clinical symptoms, usually resulting in reduced vision, proptosis, visual field alterations, color alterations, and precocious puberty [57]. King et al. studied 51 NF1 children with symptomatic OPG where $39 \%$ presented decreased visual acuity, 26\% had proptosis, $20 \%$ had precocious puberty, and $12 \%$ presented strabismus. Only $10 \%$ of patients showed visual field alterations [58]. Visual field analysis is important in the screening of patients both for glaucoma and for possible OPG [59]. However, in young children this test is not always simple to carry out due to the young age of patients, which, however, improves with learning and increasing age $[60,61]$.

Several studies demonstrated a correlation between OPGs in NF1 affected children and OCT evidenced thinning of the retinal nerve fiber layer (RNFL) [57, 62, 63]. Gu et al. found a reduction of thickness in the ganglion cell layerinner plexiform layer (GCL-IPL) in children with NF1 and OPGs and suggested this as a more reliable measure of neuronal loss with respect to RNFL thickness [64]. Current guidelines for OPG management include magnetic resonance imaging (MRI) in patients presenting with signs of OPG [65]. Chang et al. proposed the use of OCT in children with OPG [63], although the OPG task force does not make a recommendation for routine OCT testing [65]. A variation in OPG size is not always well correlated with visual outcomes; therefore, a reduction in visual acuity or alteration of visual field implicates a need to initiate or alter treatment strategy. Results of visual acuity and visual field assessment in children are not always reliable due to their young age. Furthermore, children have difficulty in cooperating with standard table mounted OCT devices; thus Avery et al. reported on the use of handheld OCT in children with OPG under sedation [11]. These authors found highly reproducible thickness measurements of the GCL-IPL and suggested that a 10\% change in the thickness of this layer should be deemed clinically significant [11]. In a recent investigation at the ophthalmology unit of the University of Rome, we used spectral domain OCT to evaluate macular neuronal and axonal thickness values 

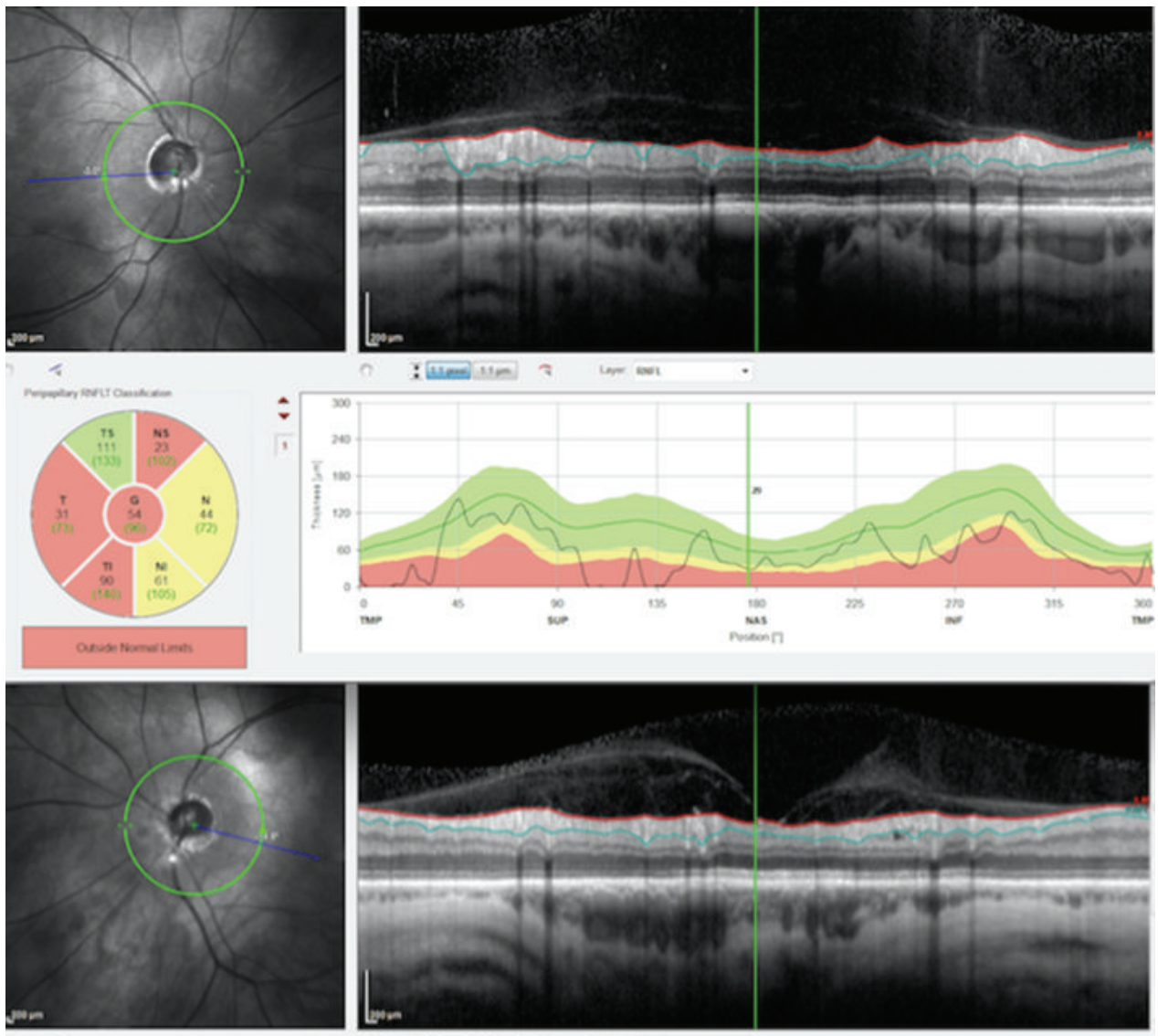

: asm ine w w
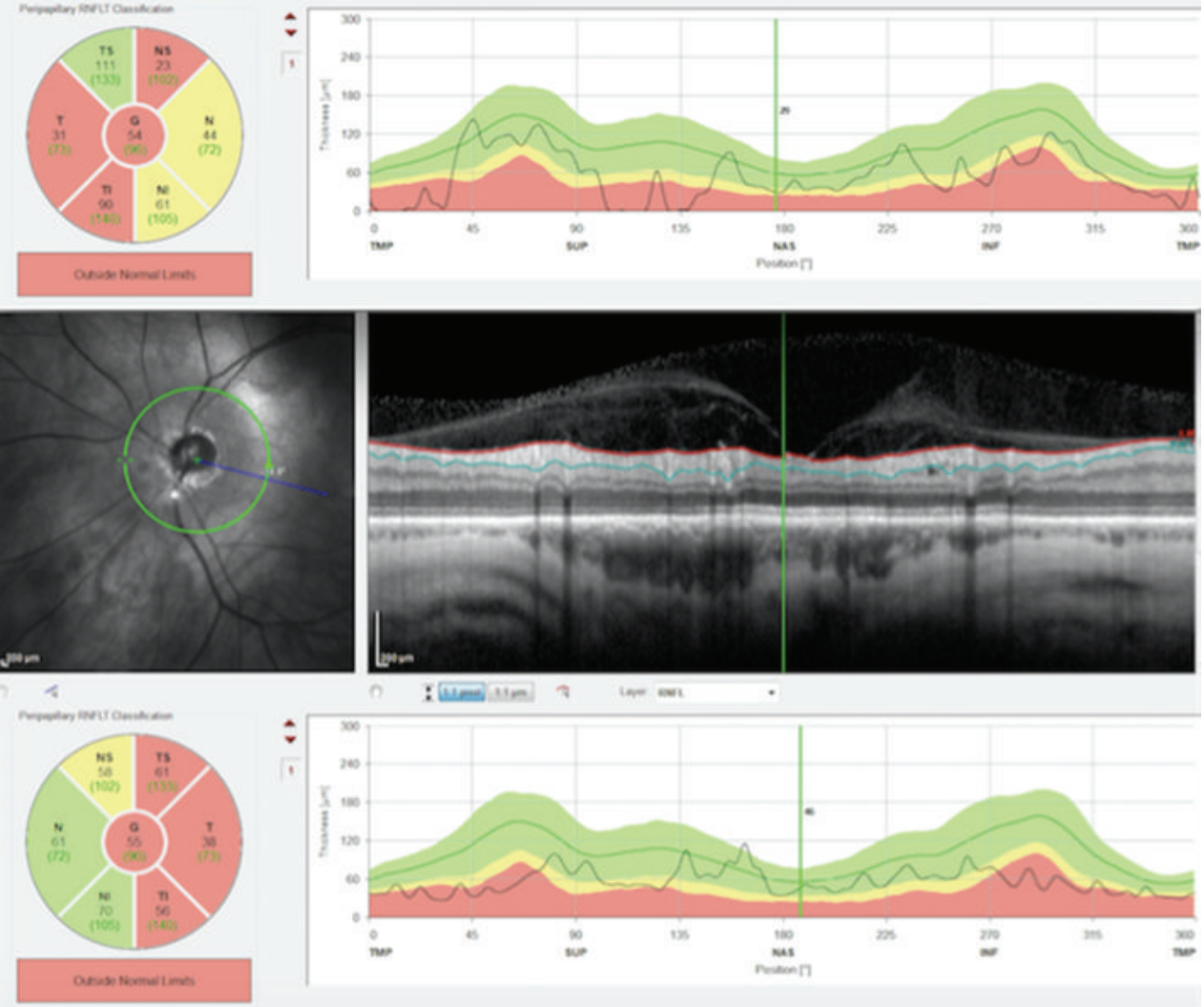

: Hen

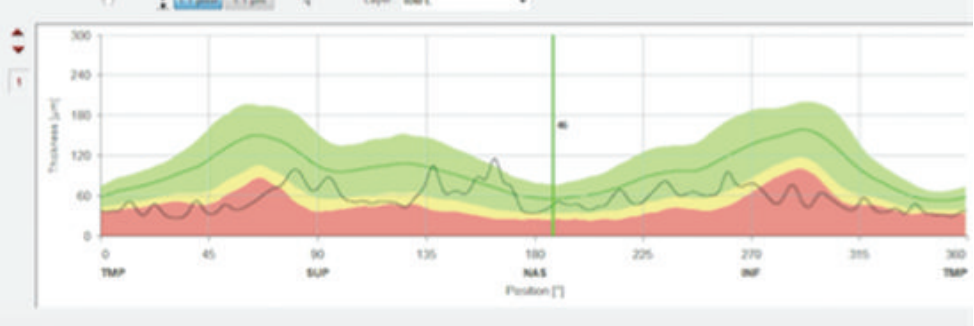

FIGURE 8: Spectral domain optical coherence tomography of the peripapillary retinal nerve fiber layer in an adult patient with neurofibromatosis type 1 showing reduction of thickness in both eyes.

in adult subjects with NF1 without OPG. We found that the peripapillary RNFL, macular RNFL, and GCL-IPL were reduced in thickness (Figure 8).

We speculated that this could be due to the age related, chronic nature of NF1 or that choroidal and retinal thinning could also involve the macular and peripapillary RNFL and the GCL-IPL [26, 66]. Furthermore, we found that the RNFL and GCL-IPL thickness values were correlated in NF1 patients; thus, we suggested the peripapillary RNFL/GCL-IPL index as a possible parameter in monitoring disease evolution [66].

Table 1 summarizes the clinical findings and diagnostic procedures in NF1.

High levels of VEGF have been demonstrated in plexiform neurofibromas and malignant peripheral nerve sheath tumors [67]. Interestingly since VEGF is produced by
Schwannoma tumor cells, systemic bevacizumab therapy has been in the management of vestibular schwannomas in neurofibromatosis type $2[68,69]$ but further research is warranted to evaluate anti-VEGF therapy in NF1.

\section{Tuberous Sclerosis Complex}

Tuberous sclerosis complex is a multisystemic disease outlined by hamartomas involving the central nervous system, eye, skin, kidneys, heart, lung, and liver. This condition was first described by Bourneville in 1880 who documented typical tuber-like cerebral lesions in the human brain at postmortem examination [70]. In 1932, Van der Hoeve described the retinal changes [1]. The mutations for the disease, discovered in 1987, are TSC1 and TSC2 located on 
TABLE 1: Clinical findings and diagnostic procedures in the phakomatoses.

\begin{tabular}{|c|c|c|c|c|}
\hline \multicolumn{3}{|c|}{ Major ophthalmic features } & \multicolumn{2}{|c|}{ Minor ophthalmic features } \\
\hline & Clinical findings & Diagnostic procedures & Clinical findings & Diagnostic procedures \\
\hline & Lisch nodules & $\begin{array}{l}\text { Slit lamp examination } \\
\text { Anterior segment OCT } \\
U B M\end{array}$ & Pulsating proptosis & $\begin{array}{l}\text { Slit lamp examination } \\
\text { Angio-MRI }\end{array}$ \\
\hline \multirow{6}{*}{ NF1 } & $\begin{array}{l}\text { Optic pathway } \\
\text { gliomas }\end{array}$ & $\begin{array}{l}\text { MRI } \\
\text { Visual field examination } \\
\text { Optic nerve head evaluation } \\
\text { RNFL OCT }\end{array}$ & Microphthalmus/enophthalmos & $\begin{array}{l}\text { Slit lamp examination } \\
\text { Ultrasound scans } \\
\text { MRI }\end{array}$ \\
\hline & \multirow{5}{*}{ Choroidal alterations } & \multirow{5}{*}{$\begin{array}{l}\text { NIR/OCT } \\
\text { ICGA }\end{array}$} & Upper eyelid plexiform fibroma & $\begin{array}{l}\text { Slit lamp examination } \\
\text { Excisional } \\
\text { biopsy/histopathology }\end{array}$ \\
\hline & & & Conjunctival neurofibroma & $\begin{array}{l}\text { Slit lamp examination } \\
\text { Excisional } \\
\text { biopsy/histopathology }\end{array}$ \\
\hline & & & Hypertrophic corneal nerves & $\begin{array}{l}\text { Slit lamp examination } \\
\text { Confocal microscopy }\end{array}$ \\
\hline & & & Glaucoma & $\begin{array}{l}\text { Slit lamp examination } \\
\text { Tonometry } \\
\text { Gonioscopy } \\
\text { Visual field examination } \\
\text { Optic nerve head evaluation } \\
\text { UBM } \\
\text { RNFL OCT }\end{array}$ \\
\hline & & & Microvascular retinal abnormalities & $\begin{array}{l}\text { Fundus examination } \\
\text { NIR } \\
\text { FAG }\end{array}$ \\
\hline \multirow{4}{*}{ TSC } & \multirow{4}{*}{$\begin{array}{l}\text { Retinal astrocytic } \\
\text { hamartomas } \\
\text { (elevated, transitional, } \\
\text { smooth) }\end{array}$} & \multirow{4}{*}{$\begin{array}{l}\text { Fundus examination } \\
\text { FAG } \\
\text { OCT }\end{array}$} & Retinal pigmentary changes & Fundus examination \\
\hline & & & Palpebral angiofibroma & $\begin{array}{l}\text { Slit lamp examination } \\
\text { Excisional } \\
\text { biopsy/histopathology }\end{array}$ \\
\hline & & & Iris/choroidal coloboma & $\begin{array}{l}\text { Slit lamp examination } \\
\text { UBM } \\
\text { Fundus examination }\end{array}$ \\
\hline & & & Iris depigmentation & Slit lamp examination \\
\hline VHL & $\begin{array}{l}\text { Retinal capillary } \\
\text { hemangioblastoma }\end{array}$ & $\begin{array}{l}\text { Fundus examination } \\
\text { FAG } \\
\text { OCT (secondary macular edema) }\end{array}$ & - & - \\
\hline
\end{tabular}

FA: fluorescein angiography; ICGA: indocyanine green angiography; MRI: magnetic resonance imaging; NF1: neurofibromatosis type 1; NIR: near infrared imaging; OCT: optical coherence tomography; RNFL OCT: retinal nerve fiber layer optical coherence tomography; TSC: tuberous sclerosis complex; UBM: ultrasound biomicroscopy; VHL: Von Hippel-Lindau disease.

chromosomes $9 \mathrm{q} 34$ and $16 \mathrm{p} 13$, which encode for hamartin and tuberin, respectively [71]. The incidence of the disease is estimated to range from $1 / 6800$ and $1 / 15000$ and the prevalence is $1 / 10,000$ with $50 \%$ to $84 \%$ of the cases being sporadic [71].

The typical retinal lesions are astrocytic hamartomas, which can be the first manifestation of disease and are among the major criteria for diagnosis. They have been reported in $44 \%$ to $48 \%$ of patients in two large case series $[72,73]$. Retinal hamartomas characterized by fibrotic astrocytes with small oval nucleus and long cytoplasmic extensions were reported by Rowley et al. in 44 of 100 (41\%) patients, with bilateral presentation in 15 cases (34\%). These hamartomas are divided into three basic morphological types: smooth, relatively flat, noncalcified, grey, translucent lesions with an oval or circular shape also known as "younger tuberous bodies"; elevated, multinodular, calcified, opaque lesions similar to mulberries also named "older tuberous bodies"; transitional lesions characterized by both features [72] (Figures 9 and 10).

The "younger tuberous bodies" are not easy to identify with ophthalmoscopy due to their translucent or blurry aspect. At times the only sign that can help to identify these lesions is a perilesional circular reflex. They are often localized near a vessel, which gives it an interrupted aspect. These vessels are usually frail and can lead to vitreous hemorrhage. The "older tuberous bodies" are usually perior epipapillary and can be confused with optic disc drusen. Their size can range between one-half and four optic disk diameters. Their structure has a high acoustic density at Bscan ultrasonography due to calcifications in the lesions. The 


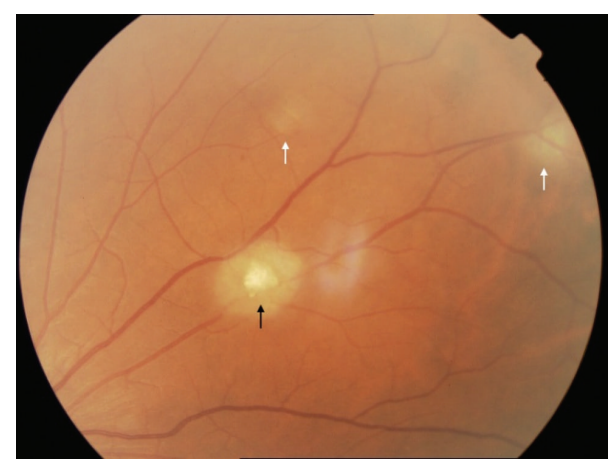

FIGURE 9: Astrocytic hamartoma of the retina in a patient with tuberous sclerosis complex. Multinodular or older tuberous body (black arrow). Translucent, blurry lesions or "younger tuberous bodies" in the periphery (white arrows).

transitional lesions have a smooth margin appearance and can be multinodular in the center. Fluorescein angiography can help to recognize the vascularization pattern and to distinguish younger from older lesions. In most cases visual acuity is not affected due to extramacular localization of lesions. Visual field defects and a progressive loss of visual acuity can be associated with optic disc hamartomas for their mechanical pushing effect [6]. Rowley et al. in a study on 179 cases reported the coexistence of more than one type of hamartoma in $30 \%$ of patients. The relatively flat hamartoma was most frequently observed (70\%), followed by the mulberry-like lesion (55\%) and the transitional type (9\%). No correlation was found between the presence and type of hamartomas and age [72].

Other features of the retina found in TSC are retinal pigmentary changes including both hyperpigmented areas (possibly due to congenital retinal pigment epithelium hypertrophy) and areas of hypopigmentation with a "punched out" appearance that can be found both at the posterior pole and in the midperiphery [74]. Rowley et al. found a statistically significant correlation between punched out areas of chorioretinal hypopigmentation and TSC and showed 39\% in the afflicted patients against $6 \%$ among controls [72].

Shields et al. studied retinal hamartomas with time domain OCT in 15 patients and found typical characteristics such as hyperreflectivity and "round, confluent, moth-eaten empty spaces with posterior shadowing" on the surface of the tumor and disorganization of the internal retinal layers. Moreover, the authors observed a gradual progression from normal to tumorous retina in all cases, inner retinal disorganization in 3 cases (20\%), outer retina disorganization in 0 cases $(0 \%)$, and disorganization of the entire retina in 5 patients (33\%). Furthermore, OCT showed moderate retinal traction over the tumor in 4 cases, optically empty spaces in 10 cases, and shadowing posterior to the tumor in 14 cases (93\%). Shallow elevation or edema of the retina adjacent to the tumor was found in $13 \%$ and $27 \%$ of cases, respectively, and macular edema was found in $20 \%$ of cases [12]. Soliman et al., using time domain OCT, differentiated OCT findings in the younger tuberous bodies where alterations were localized at the retinal nerve fiber layer with normal structure of the retinal layers and retinal pigment epithelium below, from OCT characteristics of older tuberous bodies where there was hyperreflectivity in the inner retinal layers with total shadowing of the underlying layers [75]. The translucent nature of the younger tuberous bodies could explain the absence of shadowing in these lesions [76]. Xu et al. showed that small retinal astrocytic hamartomas, undetectable with ophthalmoscopy, could be identified with infrared imaging and spectral domain OCT [77].

Other ocular findings reported by Rowley et al. included palpebral angiofibromas in 39\% of patients, nonparalytic strabismus in 5\% (4 exotropia and 1 esotropia), iris and choroidal colobomas in 3\%, and areas of iris depigmentation in $2 \%$. Myopia was present in $27 \%$, hyperopia in $22 \%$, and astigmatism ( $>0.75 \mathrm{D})$ in $27 \%$ of patients; such distribution of refractive errors is fairly similar to the distribution among normal individuals, as assessed by population studies [72]. Lopez et al. reported a case of unilateral eyelid angiofibroma with complete blepharoptosis as the presenting sign of TSC [78]. Several case reports document the association between TSC and cataract $[78,79]$, serous retinal detachment $[74,80]$, hamartomas of the iris, and hamartomas of the ciliary epithelium [81]. In some cases "ash leaf" shaped iris hypopigmentation has been observed, as shown in a patient observed in our institute [6] (Figure 11). Ocular signs rarely described include corneal leukoma, megalocornea, primary and secondary glaucoma, optic nerve atrophy, papilledema, and VI nerve palsy [82].

Table 1 summarizes the clinical findings and diagnostic procedures in TSC.

In a review by Mennel et al., flat lesions evolved to more prominent forms without symptoms in about $10 \%$ of patients but spontaneous regression was also reported [83]. Therefore, observation is only necessary unless complications arise. In cases where exudation occurs, argon laser photocoagulation and photodynamic therapy have been used [8385]. Saito et al. used intravitreal bevacizumab to treat two patients with tumor neovascularization and macular edema and found encouraging results as visual acuity and macular edema rapidly improved, tumor size decreased, and tumor associated neovascularization was rapidly attenuated [86].

Retinal toxicity has been associated with the drug vigabatrin, which is often used as first-choice therapy in the treatment of refractory seizures typical of TSC [87]. Retinal toxicity is shown with visual field loss that initiates as a bilateral nasal defect and evolves to concentric vision loss [88]. OCT of the peripapillary RNFL has shown that the alterations predominantly involve the nasal, superior, and inferior sectors [89]. Electroretinogram examination has been held as the optimal method to evaluate vigabatrin toxicity in children under nine years of age where perimetric examination is not reliable [87], but this frequently requires general anesthesia as some children cannot collaborate due to their young age or neurological condition. Thus, OCT has been proposed as a method to monitor therapy. In young children handheld OCT, especially with the eye tracker system provided by spectral domain technology, is a rapid examination during general anesthesia [11, 90, 91]. Ophthalmic monitoring is advised upon initiation of vigabatrin therapy and every three 


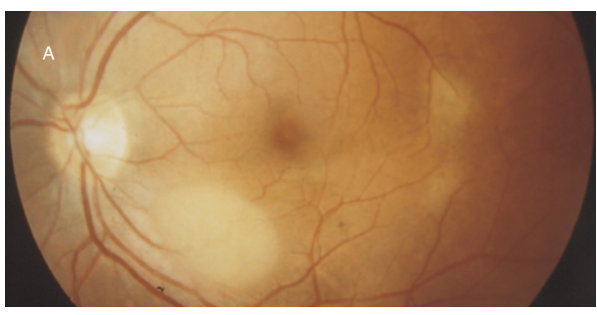

(a)

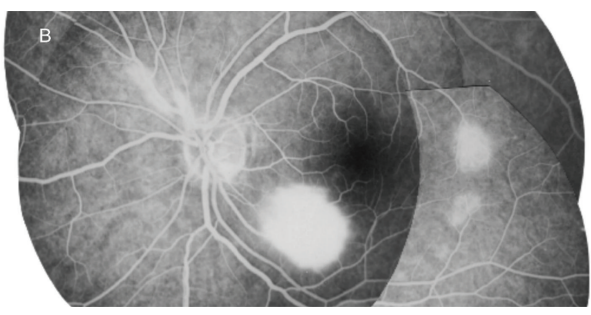

(b)

FIGURE 10: Astrocytic hamartoma of the retina in a patient with tuberous sclerosis complex. "Younger tuberous bodies" seen as smooth, flat translucent, or blurry lesions and "transitional tuberous bodies" seen as smooth, relatively flat, noncalcified, grey/white lesions with an oval or circular shape. (a) Fundus photograph and (b) corresponding fluorescein angiography image (from [6]).

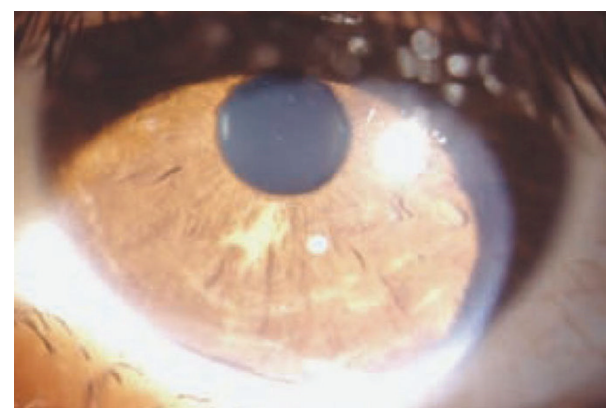

FIGURE 11: Slit lamp photograph of the anterior segment in a patient with tuberous sclerosis complex. A hypopigmented "ash leaf" shaped area is visible on the iris (from [6]).

and six months during treatment in children and adults, respectively; treatment should be suspended if there are signs of retinal toxicity [88].

\section{Von Hippel-Lindau Disease}

Von Hippel-Lindau (VHL) disease has an autosomal dominant transmission and is caused by a germline variation of the VHL tumor suppressor gene positioned on the short arm of chromosome 3p25-26 [92, 93]. Approximately 1/40,000 cases occur per year, and by age 65 years, there is close to $100 \%$ penetrance [92]. The condition is marked by the growth of numerous cysts and benign or malignant tumors in many organs. The most common characteristics of this disease are vascular tumors of the central nervous system hemangioblastoma (HB) and retinal capillary hemangioblastoma $(\mathrm{RCH})$ also referred to as hemangioma. Lesions are found more commonly in the second or third decade of life although RCHs usually occur a decade earlier than cerebellar hemangioblastomas. Increase in vascular endothelial growth factors in VHL syndrome is believed to heighten $\mathrm{RCH}$ formation and growth $[94,95]$. The most common and, most often, earliest manifestations of VHL disease are $\mathrm{RCH}$, which occur in 43 to $85 \%$ of patients [96] (Figure 12).

$\mathrm{RCH}$ are either benign vascular neoplastic processes or congenital lesions [97]. They develop from the age of 10 until 30 years similarly to $\mathrm{HB}$ in the central nervous system.

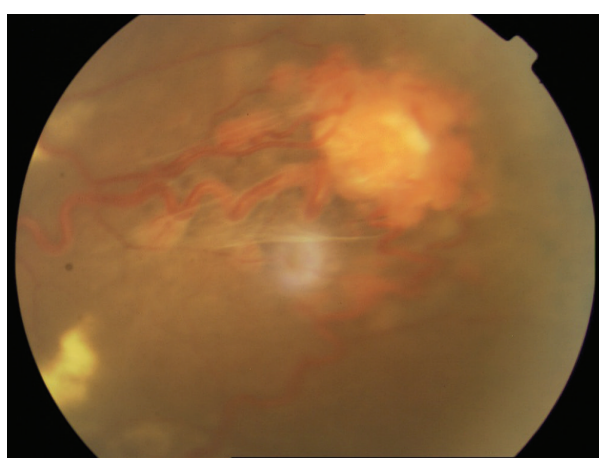

FIGURE 12: Fundus photograph of a retinal hemangioblastoma in a patient with Von Hippel-Lindau disease.

The frequency of $\mathrm{RCH}$ decreases progressively after the age of 30 years. $\mathrm{RCH}$ may remain asymptomatic for years and can regress spontaneously, but usually their growth leads to visual deterioration. They may be single or multiple tumors and are sometimes the only manifestation of the disease. Generally only a single tumor develops in one eye and it is usually asymptomatic in most patients [96]. Histopathological procedures show that RCHs are made of capillary bloodfilled spaces lined by pericytes and endothelial and stromal cells [98]. These cells are similar to those found in renal cell carcinoma and cerebellar hemangioblastoma. Based on immunohistochemical studies, it has been advanced that this type of cell may represent lipidized fibrous astrocytes and glial cells [99] or more likely vasoformative stem cells [100] that may originate from angioblasts arrested in development [101].

On ophthalmoscopic examination, RCHs are confined, globular, red-orange vascular tumors, typically observed in the juxtapapillary or the peripheral retina. They vary in size from 10 to 3000 microns or more. Peripheral lesions are most commonly found in the superior-temporal quadrant [102]. In $15 \%$ of cases RCHs are in or around an area measuring one disc diameter from the optic disk. The lesions usually have a feeder vessel where exudation and subretinal fluid can be found. Ocular complications include macular or extramacular exudation, tractional retinal detachment, new vessels on a peripheral hemangioblastoma, and neovascular glaucoma [103]. 


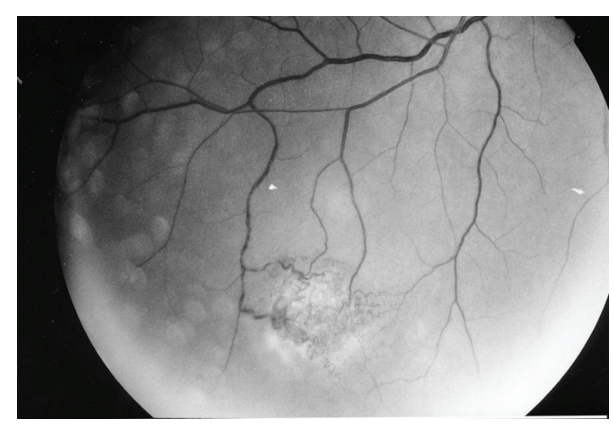

(a)

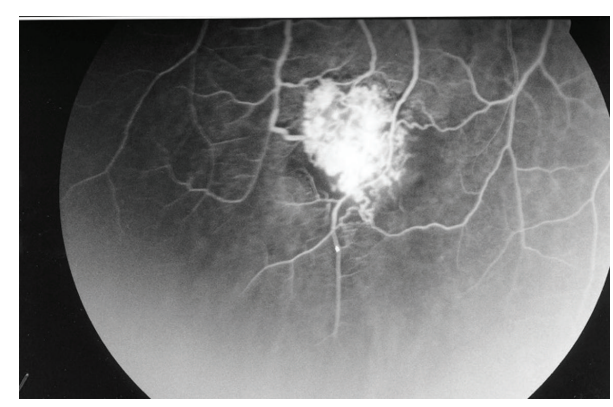

(b)

FIGURE 13: Fluorescein angiography images of a peripheral retinal hemangioblastoma in a patient with Von Hippel-Lindau disease. (a) Early red free image. (b) Late image (from [6]).

Small peripheral RCHs are sometimes difficult to detect with funduscopy and are better seen with fluorescein angiography where lesions are characterized by hyperfluorescence. The feeder vessel will hyperfluoresce and is well evidenced in the arterial phase whereas the draining vein is clearly seen in the venous phase. In the late phases the tumor shows hyperfluorescence and leakage (Figure 13).

Vessels in $\mathrm{HB}$ are fenestrated leading to exudation/ leakage in contrast to normal retinal vessels. The differential diagnosis of $\mathrm{RCH}$ is with Wyburn-Mason disease (racemose hemangioma), Coats' disease, retinal macroaneurysm, vasoproliferative retinal tumor, and retinal cavernous hemangioma [102].

Shields et al. described OCT characteristics of $\mathrm{RCH}$, which showed thickening and structural alterations of the retina with mild shadowing of the underlying structures. These authors highlighted the importance of OCT in evaluating intra- and subretinal fluid; longstanding retinal edema in these lesions had features similar to cystoid macular edema whereas the chronic persistence of subretinal edema seemed to have caused a reduction of thickness of the layer corresponding to photoreceptors [104]. Rarely exophytic $\mathrm{RCHs}$ arising from the outer retina, which do not commonly have arteriovenous shunting, have been reported in VHL disease. OCT features observed in these forms are location of the lesions in the outer retinal layers, shadowing, and photoreceptor layer rips close to the lesion [105]. OCT is also useful in evaluating the evolution of small lesions. The setback for OCT is when lesions are large and cannot be scanned due to technical limitations of the instrument [106].

Table 1 summarizes the clinical findings and diagnostic procedures in VHL disease.

Treatment of RCH usually includes laser photocoagulation, photodynamic therapy, cryotherapy, radiation, and surgical removal. In the literature various authors recommend early treatment of $\mathrm{RCH}$ when lesions tend to enlarge and become more difficult to treat with time [107]. Nevertheless, asymptomatic peripheral $\mathrm{RCH}$ lesions only require observation and treatment only in case of complications.

Singh et al. describe their experience in the management of RCH in 77 eyes of patients with VHL. Eighty-two percent of $\mathrm{RCH}$ were initially observed for a period of 84 months and the authors suggested only close observation in lesions smaller than 1500 microns, which are not visually threatening $[107,108]$. Photocoagulation with argon, krypton, and yellow dye and diode laser is effective in extrapapillary or juxtapapillary RCH where lesions are 1500 microns or less in size and localized in the posterior retina $[107,108]$. Cryotherapy has been used for the treatment of extrapapillary RCHs [105]. Singh et al. performed cryotherapy in lesions larger than 3000 microns and treated extrapapillary $\mathrm{RCH}$ with a mean size of 4500 microns with iodine-125 plaque with good results [108]. Thermotherapy, external bean radiotherapy, pars plana vitrectomy, and related procedures are more frequently used to treat the juxtapapillary locations of RCH [108].

Photodynamic therapy (PDT) is aimed at vascular endothelial cells and has also been employed in the management of RCH $[109,110]$. However, when a hemangioblastoma is associated with the optic nerve, such treatment can result in loss of vision. Therefore, VEGF-targeted strategies have been tested but therapy outcomes are contrasting [107, 111, 112]. SU5416 is an inhibitor of VEGF receptor-2, which was used through intravenous administration in a case of $\mathrm{RCH}$ of the optic nerve head and in a single case of a juxtapapillary $\mathrm{RCH}$ and improved visual acuity and visual field without reducing the size of the tumor $[113,114]$. Madhusudan et al. found stability or improvement in the ocular lesions in 2 out of 6 patients treated with SU5416 [115]. Intravitreal bevacizumab associated with photodynamic therapy showed tumor regression and reduction of exudation [112], whereas pegaptanib only reduced exudation with no effect on tumor size [116]. Wong et al. published their results on 5 cases treated with intravitreal ranibizumab and reported that in two patients with large juxtapapillary lesions associated with circinate lipid, intraretinal hemorrhage, and marked retinal edema extending into the macula this therapy did not exert any beneficial effect whereas it was successful in a patient with a juxtapapillary endophytic lesion of one disk diameter with limited retinal edema not involving the fovea [111]. They concluded that intravitreal ranibizumab does not have a beneficial action on the largest and most exudative lesions but is efficacious in small lesions [111]. Therefore, effectiveness and appropriateness of treatment are influenced by the site and size of $\mathrm{RCH}$; treatment cannot be delivered 
to juxtapapillary RCHs without damage to the optic nerve whereas it can be applied to the peripheral retina [117]. Today intravitreal anti-VEGF treatment is successfully used in a wider array of retinal pathologies and recently in metastatic tumors of the choroid [118-122]. A principal motive for unsuccessful outcome of this treatment may be the size of hamartomatous lesions in VHL disease, which can be considerably greater than choroidal neovascular membranes [123]. Moreover, the mature vasculature of the hamartomas and genetic alterations underlying the phakomatoses leading to incessant production of VEGF can result in poor response $[111,123]$.

\section{Conclusions}

The phakomatoses require a multidisciplinary approach and the ophthalmologist plays a fundamental role in diagnosis and management. Imaging techniques in ophthalmology have made groundbreaking progress in the past decade and NIR may lead to the inclusion of choroidal nodules as the 8th diagnostic criteria in NF1. OCT provides novel information on retinal hamartomas and enhanced depth imaging technology enables visualization of the choroid in vivo providing further information on the morphology of the choroid and choroidal nodules in NF1. Peripapillary RNFL analysis with OCT is a noninvasive tool and is an adjunct in monitoring optic pathway gliomas. Furthermore, handheld OCT enables faster examination of the RNFL in children who are unable to collaborate due to their young age and neurological conditions. An enormous bulk of research has led to the establishment of optimal doses and protocols for intravitreal anti-VEGF treatment in retinal pathology, but little information is available for this treatment in the phakomatoses and reports on the use of anti-VEGF agents are contrasting and incomplete. The future might hold new drug delivery systems for the intravitreal treatment of symptomatic retinal hamartomas.

\section{Competing Interests}

The authors report no competing interests or financial support regarding this paper.

\section{References}

[1] J. Van der Hoeve, “The Doyne memorial lecture: eye symptoms in the phakomatoses," Transactions of the Ophthalmological Societies of the United Kingdom, vol. 52, pp. 380-401, 1932.

[2] M. J. Hogan and L. E. Zimmerman, Ophthalmic Pathology: An Atlas and Textbook, WB Saunders, Philadelphia, Pa, USA, 2nd edition, 1962.

[3] C. F. Parsa, "Focal venous hypertension as a pathophysiologic mechanism for tissue hypertrophy, port-wine stains, the SturgeWeber syndrome, and related disorders: proof of concept with novel hypothesis for underlying etiological cause (an American Ophthalmological Society thesis)," Transactions of the American Ophthalmological Society, vol. 111, pp. 180-207, 2013.

[4] S. Abdolrahimzadeh, V. Scavella, L. Felli, F. Cruciani, M. T. Contestabile, and S. M. Recupero, "Ophthalmic alterations in the sturge-weber syndrome, klippel-trenaunay syndrome, and the phakomatosis pigmentovascularis: an independent group of conditions?" BioMed Research International, vol. 2015, Article ID 786519, 11 pages, 2015.

[5] S. M. Recupero, S. Abdolrahimzadeh, M. De Dominicis, and R. Mollo, "Sturge-Weber syndrome associated with naevus of Ota," Eye, vol. 12, no. 2, pp. 212-213, 1998.

[6] S. M. Recupero, S. Abdolrahimzadeh, G. Lepore et al., Lapparato Oculare Nelle Sindromi Neurocutanee, Verduci, Rome, Italy, 2004.

[7] K. Cichowski and T. Jacks, "NF1 tumor suppressor gene function: narrowing the GAP," Cell, vol. 104, no. 4, pp. 593-604, 2001.

[8] R. R. Lonser, G. M. Glenn, M. Walther et al., "von HippelLindau disease," The Lancet, vol. 361, no. 9374, pp. 2059-2067, 2003.

[9] R. S. Yeung, "Multiple roles of the tuberous sclerosis complex genes," Genes Chromosomes and Cancer, vol. 38, no. 4, pp. 368375, 2003.

[10] R. Parrozzani, M. Clementi, L. Frizziero et al., "In vivo detection of Choroidal abnormalities related to NF1: feasibility and comparison with standard NIH diagnostic criteria in pediatric patients," Investigative Ophthalmology and Visual Science, vol. 56, no. 10, pp. 6036-6042, 2015.

[11] R. A. Avery, A. Cnaan, J. S. Schuman et al., "Intra- and inter-visit reproducibility of ganglion cell-inner plexiform layer measurements using handheld optical coherence tomography in children with optic pathway gliomas," American Journal of Ophthalmology, vol. 158, no. 5, pp. 916-923, 2014.

[12] C. L. Shields, R. Benevides, M. A. Materin, and J. A. Shields, "Optical coherence tomography of retinal astrocytic hamartoma in 15 cases," Ophthalmology, vol. 113, no. 9, pp. 1553-1557, 2006.

[13] K. Jett and J. M. Friedman, "Clinical and genetic aspects of neurofibromatosis 1," Genetics in Medicine, vol. 12, no. 1, pp. 1-11, 2010.

[14] V. M. Riccardi, "Neurofibromatosis: past, present, and future," The New England Journal of Medicine, vol. 324, no. 18, pp. 12831285, 1991.

[15] A. C. Hirbe and D. H. Gutmann, "Neurofibromatosis type 1: a multidisciplinary approach to care," The Lancet Neurology, vol. 13, no. 8, pp. 834-843, 2014.

[16] National Institutes of Health Consensus Development, "Neurofibromatosis. Conference statement," Archives of Neurology, vol. 45 , no. 5 , pp. $575-578,1988$.

[17] J. C. Noonan Carey, "Neurofibromatosis-noonan syndrome," American Journal of Medical Genetics A, vol. 75, no. 3, pp. 263264, 1998.

[18] M. Ruggieri, P. Pavone, A. Polizzi et al., "Ophthalmological manifestations in segmental neurofibromatosis type 1," British Journal of Ophthalmology, vol. 88, no. 11, pp. 1429-1433, 2004.

[19] S. Abdolrahimzadeh, D. C. Piraino, R. Plateroti, G. Scuderi, and S. M. Recupero, "Ocular alterations in a rare case of segmental neurofibromatosis type 1 with a non-classified mutational variant of the NF-1 gene," Ophthalmic Genetics, vol. 37, no. 2, pp. 214-216, 2016.

[20] M. Coban-Karatas, R. Altan-Yaycioglu, N. Bal, and Y. A. Akova, "Management of facial disfigurement in orbitotemporal neurofibromatosis," Ophthalmic Plastic and Reconstructive Surgery, vol. 26, no. 2, pp. 124-126, 2010.

[21] C. B. Gabrieli, S. M. Recupero, M. T. Contestabile, E. Pacella, and S. Abdolrahimzadeh, "Fox's modified technique in 
the management of blepharoptosis," Ophthalmic Surgery and Lasers, vol. 27, pp. 924-928, 1996.

[22] N. Scuderi, S. Chiummariello, F. De Gado, C. Alfano, G. Scuderi, and S. M. Recupero, "Surgical correction of blepharoptosis using the levator aponeurosis-Müller's muscle complex readaptation technique: a 15-year experience," Plastic and Reconstructive Surgery, vol. 121, no. 1, pp. 71-78, 2008.

[23] B. S. Shaheen, M. Bakir, and S. Jain, "Corneal nerves in health and disease," Survey of Ophthalmology, vol. 59, no. 3, pp. 263285, 2014.

[24] M.-A. Javadi, M. R. Kanavi, A. Faramarzi, S. Feizi, F. Azizi, and F. Javadi, "Confocal scan imaging and impression cytology of the cornea in a case of multiple endocrine neoplasia type-2b," Journal of Ophthalmic and Vision Research, vol. 7, no. 2, pp. 176179, 2012.

[25] E. Pacella, S. Abdolrahimzadeh, and C. Balacco Gabrieli, "Excimer laser photorefractive keratectomy for hyperopia," Ophthalmic Surgery and Lasers, vol. 32, no. 1, pp. 30-34, 2001.

[26] S. Abdolrahimzadeh, L. Felli, R. Plateroti et al., "Morphologic and vasculature features of the choroid and associated choroidretinal thickness alterations in neurofibromatosis type 1," British Journal of Ophthalmology, vol. 99, no. 6, pp. 789-793, 2015.

[27] S. M. Recupero, R. Plateroti, S. Abdolrahimzadeh et al., "Lisch nodules in neurofibromatosis type 1: relationship to age and cutaneous neurofibromas," Annals of OphthalmologyGlaucoma, vol. 28, no. 3, pp. 178-183, 1996.

[28] N. K. Ragge, R. E. Falk, W. E. Cohen, and A. L. Murphree, "Images of Lisch nodules across the spectrum," Eye, vol. 7, no. 1, pp. 95-101, 1993.

[29] C. Cassiman, E. Legius, W. Spileers, and I. Casteels, "Ophthalmological assessment of children with neurofibromatosis type 1," European Journal of Pediatrics, vol. 172, no. 10, pp. 1327-1333, 2013.

[30] S. Makino, H. Tampo, Y. Arai, and H. Obata, "Correlations between choroidal abnormalities, lisch nodules, and age in patients with neurofibromatosis type 1," Clinical Ophthalmology, vol. 8, pp. 165-168, 2014.

[31] G. R. Beuchamp, "Neurofibromatosis type 1 in children," Transactions of the American Ophthalmological Society, vol. 93, pp. 445-472, 1995.

[32] N. K. Ragge, J. Acheson, and A. L. Murphree, "Iris mammillations: significance and associations," Eye, vol. 10, no. 1, pp. 86-91, 1996.

[33] A. M. Plateroti, V. Scavella, B. Abdolrahimzadeh et al., "An update on oculodermal melanosis and rare associated conditions," Seminars in Ophthalmology, 2016.

[34] S. Emre, M. Palamar, M. O. Ulusoy, and G. Gençoğlan, "Ciliary body cysts in neurofibromatosis: a new coexistence?" Graefe's Archive for Clinical and Experimental Ophthalmology, vol. 250, no. 6, pp. 857-861, 2012.

[35] S. H. Al Freihi, D. P. Edward, S. R. Nowilaty, M. A. Abouammoh, and J. Morales, "Iris neovascularization and neovascular glaucoma in neurofibromatosis type 1: report of 3 cases in children," Journal of Glaucoma, vol. 22, no. 4, pp. 336-341, 2013.

[36] F. Mantelli, S. Abdolrahimzadeh, G. Mannino, and A. Lambiase, "Unusual case of angle closure glaucoma in a patient with neurofibromatosis type 1," Case Reports in Ophthalmology, vol. 5, no. 3, pp. 386-391, 2014.

[37] W. Nolan, "Anterior segment imaging: ultrasound biomicroscopy and anterior segment optical coherence tomography," Current Opinion in Ophthalmology, vol. 19, no. 2, pp. 115-121, 2008.
[38] G. Mannino, R. Malagola, S. Abdolrahimzadeh, G. M. Villani, and S. M. Recupero, "Ultrasound biomicroscopy of the peripheral retina and the ciliary body in degenerative retinoschisis associated with pars plana cysts," British Journal of Ophthalmology, vol. 85, no. 8, pp. 976-982, 2001.

[39] F. Cruciani, M. Lorenzatti, V. Nazzarro, and S. Abdolrahimzadeh, "Bilateral acute angle closure glaucoma and myopia induced by topiramate," La Clinica Terapeutica, vol. 160, no. 3, pp. 215-216, 2009.

[40] J. Morales, I. A. Chaudhry, and T. M. Bosley, "Glaucoma and globe enlargement associated with neurofibromatosis type 1 ," Ophthalmology, vol. 116, no. 9, pp. 1725-1730, 2009.

[41] K. C. Okafor and J. D. Brandt, "Measuring intraocular pressure," Current Opinion in Ophthalmology, vol. 26, no. 2, pp. 103-109, 2015.

[42] G. L. Scuderi, N. C. Cascone, F. Regine, A. Perdicchi, A. Cerulli, and S. M. Recupero, "Validity and limits of the rebound tonometer (ICare ${ }^{\circledR}$ ): clinical study," European Journal of Ophthalmology, vol. 21, no. 3, pp. 251-257, 2011.

[43] D. E. Patel, P. M. Cumberland, B. C. Walters, I. Russell-Eggitt, M. Cortina-Borja, and J. S. Rahi, "Study of Optimal Perimetric Testing in Children (OPTIC) normative visual field values in children presented at: the Royal College of Ophthalmologists Annual Congress, May 2014, Birmingham, UK,' Ophthalmology, vol. 122, no. 8, pp. 1711-1717, 2015.

[44] S. M. Recupero, M. T. Contestabile, L. Taverniti, G. M. Villani, and V. Recupero, "Open-angle glaucoma: variations in the intraocular pressure after visual field examination," Journal of Glaucoma, vol. 12, no. 2, pp. 114-118, 2003.

[45] C. Rescaldani, P. Nicolini, G. Fatigati, and F. G. Bottoni, "Clinical application of digital indocyanine green angiography in choroidal neurofibromatosis," Ophthalmologica, vol. 212, no. 2, pp. 99-104, 1998.

[46] T. Yasunari, K. Shiraki, H. Hattori, and T. Miki, "Frequency of choroidal abnormalities in neurofibromatosis type 1," The Lancet, vol. 356, no. 9234, pp. 988-992, 2000.

[47] F. Viola, E. Villani, F. Natacci et al., "Choroidal abnormalities detected by near-infrared reflectance imaging as a new diagnostic criterion for neurofibromatosis 1," Ophthalmology, vol. 119, no. 2, pp. 369-375, 2012.

[48] R. F. Spaide, H. Koizumi, and M. C. Pozonni, "Enhanced depth imaging spectral-domain optical coherence tomography," American Journal of Ophthalmology, vol. 146, no. 4, pp. 496-500, 2008.

[49] A. Ayata, M. Ünal, D. Ersanli, and S. Tatlipinar, "Near infrared fluorescence and OCT features of choroidal abnormalities in type 1 neurofibromatosis," Clinical and Experimental Ophthalmology, vol. 36, no. 4, pp. 390-392, 2008.

[50] R. C. Rao and N. Choudhry, "Enhanced depth imaging spectraldomain optical coherence tomography findings in choroidal neurofibromatosis," Ophthalmic Surgery Lasers and Imaging Retina, vol. 45, no. 5, pp. 466-468, 2014.

[51] R. Muci-Mendoza, M. Ramella, and D. Fuenmayor-Rivera, "Corkscrew retinal vessels in neurofibromatosis type 1: report of 12 cases," British Journal of Ophthalmology, vol. 86, no. 3, pp. 282-284, 2002.

[52] S. Abdolrahimzadeh, L. Felli, D. C. Piraino, R. Mollo, S. Calvieri, and S. M. Recupero, "Retinal microvascular abnormalities overlying choroidal nodules in neurofibromatosis type 1," $B M C$ Ophthalmology, vol. 14, article 146, 2014. 
[53] M. Destro, D. J. D’Amico, E. S. Gragoudas et al., "Retinal manifestations of neurofibromatosis: diagnosis and management," Archives of Ophthalmology, vol. 109, no. 5, pp. 662-666, 1991.

[54] C. L. Shields, A. Mashayekhi, V. V. Dai, M. A. Materin, and J. A. Shields, "Optical coherence tomographic findings of combined hamartoma of the retina and retinal pigment epithelium in 11 patients," Archives of Ophthalmology, vol. 123, no. 12, pp. 17461750, 2005.

[55] H. M. Kang, H. J. Koh, and E. J. Chung, "Spectral-domain optical coherence tomography of combined hamartoma of the retina and retinal pigment epithelium in neurofibromatosis," Korean Journal of Ophthalmology, vol. 27, no. 1, pp. 68-71, 2013.

[56] R. Listernick, R. E. Ferner, G. T. Liu, and D. H. Gutmann, "Optic pathway gliomas in neurofibromatosis-1: controversies and recommendations," Annals of Neurology, vol. 61, no. 3, pp. 189-198, 2007.

[57] R. A. Avery, G. T. Liu, M. J. Fisher et al., "Retinal nerve fiber layer thickness in children with optic pathway gliomas," American Journal of Ophthalmology, vol. 151, no. 3, pp. 542-549, 2011.

[58] A. King, R. Listernick, J. Charrow, L. Piersall, and D. H. Gutmann, "Optic pathway gliomas in neurofibromatosis type 1: the effect of presenting symptoms on outcome," American Journal of Medical Genetics, vol. 122, no. 2, pp. 95-99, 2003.

[59] M. Iester, A. Perdicchi, E. Capris, A. Siniscalco, G. Calabria, and S. M. Recupero, "Comparison between discriminant analysis models and 'Glaucoma Probability Score' for the detection of glaucomatous optic nerve head changes," Journal of Glaucoma, vol. 17, no. 7, pp. 535-540, 2008.

[60] D. E. Patel, P. M. Cumberland, B. C. Walters et al., "Study of optimal perimetric testing in children (OPTIC): feasibility, reliability and repeatability of perimetry in children," PLOS ONE, vol. 10, no. 6, Article ID e0130895, 2015.

[61] C. M. Teresa, P. Andrea, A. Stefano, R. Vincenzo, and S. M. Recupero, "The influence of learning effect on frequency doubling technology perimetry (Matrix)," Journal of Glaucoma, vol. 16, no. 3, pp. 297-301, 2007.

[62] R. Parrozzani, M. Clementi, O. Kotsafti et al., "Optical coherence tomography in the diagnosis of optic pathway gliomas," Investigative Ophthalmology \& Visual Science, vol. 54, no. 13, pp. 8112-8118, 2013.

[63] L. Chang, M. A. El-Dairi, T. A. Frempong et al., "Optical coherence tomography in the evaluation of neurofibromatosis type-1 subjects with optic pathway gliomas," Journal of AAPOS, vol. 14, no. 6, pp. 511-517, 2010.

[64] S. Gu, N. Glaug, A. Cnaan, R. J. Packer, and R. A. Avery, "Ganglion cell layer-inner plexiform layer thickness and vision loss in young children with optic pathway gliomas," Investigative Ophthalmology and Visual Science, vol. 55, no. 3, pp. 1402-1408, 2014.

[65] R. Listernick, D. N. Louis, R. J. Packer, and D. H. Gutmann, "Optic pathway gliomas in children with neurofibromatosis 1: consensus statement from the NF1 optic pathway glioma task force," Annals of Neurology, vol. 41, no. 2, pp. 143-149, 1997.

[66] S. Abdolrahimzadeh, L. Felli, A. M. Plateroti, A. Perdicchi, M. T. Contestabile, and S. M. Recupero, "Spectral domain optical coherence tomography evidence of retinal nerve fiber layer and ganglion cell loss in adult patients with neurofibromatosis type 1," Retina, vol. 36, no. 1, pp. 75-81, 2016.

[67] R. E. Friedrich, C. Beer, M. Glatzel, and C. Hagel, "Vascular endothelial growth factor, basic fibroblast growth factor and epithelial growth factor receptor in peripheral nerve sheath tumors of neurofibromatosis type 1," Anticancer Research, vol. 35, no. 1, pp. 137-144, 2015.

[68] S. R. Plotkin, A. O. Stemmer-Rachamimov, F. G. Barker II et al., "Hearing improvement after bevacizumab in patients with neurofibromatosis type 2," The New England Journal of Medicine, vol. 361, no. 4, pp. 358-367, 2009.

[69] S. R. Plotkin, V. L. Merker, C. Halpin et al., "Bevacizumab for progressive vestibular schwannoma in neurofibromatosis type 2: a retrospective review of 31 patients," Otology \& Neurotology, vol. 33, no. 6, pp. 1046-1052, 2012.

[70] D. M. Bourneville, "Sclerose tubéreuse des circonvolutions cérébrales: idiotie et épilepsie hémiplegique," Archives of Neurology, vol. 1, pp. 81-91, 1880.

[71] W. C. Wiederholt, M. R. Gomez, and L. T. Kurland, "Incidence and prevalence of tuberous sclerosis in rochester, minnesota, 1950 through 1982," Neurology, vol. 35, no. 4, pp. 600-603, 1985.

[72] S. A. Rowley, F. J. O'Callaghan, and J. P. Osborne, "Ophthalmic manifestations of tuberous sclerosis: a population based study," British Journal of Ophthalmology, vol. 85, no. 4, pp. 420-423, 2001.

[73] J. H. Nyboer, D. M. Robertson, and M. R. Gomez, "Retinal lesions in tuberous sclerosis," Archives of Ophthalmology, vol. 94, no. 8, pp. 1277-1280, 1976.

[74] J. Dutta, "A rare case of visual loss due to serous detachment associated with retinal 'mulberry' hamartoma in a case of tuberous sclerosis," Journal of Ocular Biology, Diseases, and Informatics, vol. 5, no. 3-4, pp. 51-53, 2012.

[75] W. Soliman, M. Larsen, B. Sander, M. Wegener, and D. Milea, "Optical coherence tomography of astrocytic hamartomas in tuberous sclerosis," Acta Ophthalmologica Scandinavica, vol. 85, no. 4, pp. 454-455, 2007.

[76] B. Chanana and V. Kumar, "Imaging findings in tuberous sclerosis with multiple retinal astrocytic hamartomas," Journal of Pediatric Ophthalmology and Strabismus, vol. 48, no. 2, pp. 127-128, 2011.

[77] L. Xu, T. R. Burke, J. P. Greenberg, V. B. Mahajan, and S. H. Tsang, "Infrared imaging and optical coherence tomography reveal early-stage astrocytic hamartomas not detectable by fundoscopy," American Journal of Ophthalmology, vol. 153, no. 5, pp. 883-889.e2, 2012.

[78] J. P. Lopez, D. Ossandón, P. Miller, L. Sánchez, and A. Winter, "Unilateral eyelid angiofibroma with complete blepharoptosis as the presenting sign of tuberous sclerosis," Journal of AAPOS, vol. 13, no. 4, pp. 413-414, 2009.

[79] J. E. A. Warner and S. Lessell, "Cataract in tuberous sclerosis," Journal of Neuro-Ophthalmology, vol. 17, no. 1, pp. 33-35, 1997.

[80] S.-J. Lee, Y.-H. Kim, J.-H. Lee, S.-H. Rah, H.-W. Shin, and B.-K. Han, "Development of parafoveal exudates and serous retinal detachment in a pregnant woman with tuberous sclerosis," Gynecologic and Obstetric Investigation, vol. 53, no. 3, pp. 188190, 2002.

[81] R. C. Eagle Jr., J. A. Shields, C. L. Shields, and M. G. Wood, "Hamartomas of the iris and ciliary epithelium in tuberous sclerosis complex," Archives of Ophthalmology, vol. 118, no. 5, pp. 711-715, 2000.

[82] D. M. Robertson, "Ophthalmic manifestations of tuberous sclerosis," Annals of the New York Academy of Sciences, vol. 615, pp. 17-25, 1991.

[83] S. Mennel, N. Hausmann, C. H. Meyer, and S. Peter, "Photodynamic therapy for exudative hamartoma in tuberous sclerosis," Archives of Ophthalmology, vol. 124, no. 4, pp. 597-599, 2006. 
[84] T. R. Vrabec and J. J. Augsburger, "Exudative retinal detachment due to small noncalcified retinal astrocytic hamartoma," American Journal of Ophthalmology, vol. 136, no. 5, pp. 952-954, 2003.

[85] R. D. Harley and W. D. Grove, "Tuberous sclerosis: description and report of 12 cases," Annals of Ophthalmology, vol. 1, pp. 477481, 1970.

[86] W. Saito, S. Kase, K. Ohgami, S. Mori, and S. Ohno, "Intravitreal anti-vascular endothelial growth factor therapy with bevacizumab for tuberous sclerosis with macular oedema," Acta Ophthalmologica, vol. 88, no. 3, pp. 377-380, 2010.

[87] L. Hébet-Lalonde, L. Carmant, P. Major et al., "Electrophysiological evidences of visual field alterations in children exposed to vigabatrin early in life," Pediatric Neurology, 2016.

[88] P. Kotagal, "Limiting retinal toxicity of vigabatrin in children with infantile spasms," Epilepsy Currents, vol. 15, no. 6, pp. 327329, 2015.

[89] C. Origlieri, B. Geddie, B. Karwoski et al., "Optical coherence tomography to monitor vigabatrin toxicity in children," Journal of American Association for Pediatric Ophthalmology and Strabismus, vol. 20, no. 2, pp. 136-140, 2016.

[90] C. Gerth, R. J. Zawadzki, E. Héon, and J. S. Werner, "Highresolution retinal imaging in young children using a handheld scanner and Fourier-domain optical coherence tomography," Journal of AAPOS, vol. 13, no. 1, pp. 72-74.e1, 2009.

[91] R. S. Maldonado, J. A. Izatt, N. Sarin et al., "Optimizing handheld spectral domain optical coherence tomography imaging for neonates, infants, and children," Investigative Ophthalmology and Visual Science, vol. 51, no. 5, pp. 2678-2685, 2010.

[92] R. R. Lonser, G. M. Glenn, M. Walther et al., "Von HippelLindau disease," The Lancet, vol. 361, no. 9374, pp. 2059-2067, 2003.

[93] F. Latif, K. Tory, J. Gnarra et al., "Identification of the von Hippel-Lindau disease tumor suppressor gene," Science, vol. 260, no. 5112, pp. 1317-1320, 1993.

[94] W. G. Kaelin Jr., "The von hippel-lindau gene, kidney cancer, and oxygen sensing," Journal of the American Society of Nephrology, vol. 14, no. 11, pp. 2703-2711, 2003.

[95] C.-C. Chan, A. O. Vortmcyer, E. Y. Chew et al., "VHL gene deletion and enhanced VEGF gene expression detected in the stromal cells of retinal angioma," Archives of Ophthalmology, vol. 117, no. 5, pp. 625-630, 1999.

[96] W. T. Wong and E. Y. Chew, "Ocular von Hippel-Lindau disease: clinical update and emerging treatments," Current Opinion in Ophthalmology, vol. 19, no. 3, pp. 213-217, 2008.

[97] R. L. Font and A. P. Ferry, “The phakomatoses", International Ophthalmology Clinics, vol. 12, no. 1, pp. 1-50, 1972.

[98] W. R. Green, "Retina: capillary hemangioma," in Ophthalmic Pathology: An atlas and Textbook, W. H. Spencer, Ed., pp. 709718, WB Saunders, Philadelphia, Pa, USA, 1996.

[99] H. E. Grossniklaus, J. W. Thomas, N. Vigneswaran, and W. H. Jarrett III, "Retinal hemangioblastoma: a histologic, immunohistochemical, and ultrastructural evaluation," Ophthalmology, vol. 99, no. 1, pp. 140-145, 1992.

[100] L. Mottow Lippa, M. O. M. Tso, G. A. Peyman, and G. Chejfec, "Von Hippel angiomatosis. A light, electron microscopic, and immunoperoxidase characterization," Ophthalmology, vol. 90, no. 7, pp. 848-855, 1983.

[101] A. O. Vortmeyer, S. Frank, S.-Y. Jeong et al., "Developmental arrest of angioblastic lineage initiates tumorigenesis in von Hippel-Lindau disease," Cancer Research, vol. 63, no. 21, pp. 7051-7055, 2003.
[102] N. M. N. Haddad, J. D. Cavallerano, and P. S. Silva, "Von hippel-lindau disease: a genetic and clinical review," Seminars in Ophthalmology, vol. 28, no. 5-6, pp. 377-386, 2013.

[103] H. Dollfus, P. Massin, P. Taupin et al., "Retinal hemangioblastoma in von Hippel-Lindau disease: a clinical and molecular study," Investigative Ophthalmology \& Visual Science, vol. 43, no. 9, pp. 3067-3074, 2002.

[104] C. L. Shields, M. A. Materin, and J. A. Shields, "Review of optical coherence tomography for intraocular tumors," Current Opinion in Ophthalmology, vol. 16, no. 3, pp. 141-154, 2005.

[105] E. K. Chin, R. Trikha, L. S. Morse, R. J. Zawadzki, J. S. Werner, and S. S. Park, "Optical coherence tomography findings of exophitic retinal capillary hemangiomas of the posterior pole," Ophthalmic Surgery, Lasers and Imaging Retina, vol. 42, pp. E1E5, 2010.

[106] V. G. Grigoropoulos, P. Nikolaidis, I. Emfietzoglou, P. G. Theodossiadis, and G. P. Theodossiadis, "Evolution of a juxtapapillary von Hippel-Lindau tumour examined by optical coherence tomography," Clinical and Experimental Optometry, vol. 95, no. 2, pp. 237-240, 2012.

[107] D. Schmidt, E. Natt, and H. P. Neumann, "Long-term results of laser treatment for retinal angiomatosis in von Hippel-Lindau disease," European Journal of Medical Research, vol. 5, no. 2, pp. 47-58, 2000.

[108] A. D. Singh, M. Nouri, C. L. Shields, J. A. Shields, and N. Perez, "Treatment of retinal capillary hemangioma," Ophthalmology, vol. 109, no. 10, pp. 1799-1806, 2002.

[109] U. Schmidt-Erfurth, T. Hasan, E. Gragoudas, N. Michaud, T. J. Flotte, and R. Birngruber, "Vascular targeting in photodynamic occlusion of subretinal vessels," Ophthalmology, vol. 101, no. 12, pp. 1953-1961, 1994.

[110] U. Schmidt-Erfurth, H. Laqua, U. Schlötzer-Schrehard, A. Viestenz, and G. O. H. Naumann, "Histopathological changes following photodynamic therapy in human eyes," Archives of Ophthalmology, vol. 120, no. 6, pp. 835-844, 2002.

[111] W. T. Wong, K. J. Liang, K. Hammel, H. R. Coleman, and E. Y. Chew, "Intravitreal ranibizumab therapy for retinal capillary hemangioblastoma related to von Hippel-Lindau disease," Ophthalmology, vol. 115, no. 11, pp. 1957-1964.e3, 2008.

[112] F. Ziemssen, M. Voelker, W. Inhoffen, K. U. Bartz-Schmidt, and F. Gelisken, "Combined treatment of a juxtapapillary retinal capillary haemangioma with intravitreal bevacizumab and photodynamic therapy," Eye, vol. 21, no. 8, pp. 1125-1126, 2007.

[113] L. P. Aiello, D. J. George, M. T. Cahill et al., "Rapid and durable recovery of visual function in a patient with von Hippel-Lindau syndrome after systemic therapy with vascular endothelial growth factor receptor inhibitor SU5416," Ophthalmology, vol. 109, no. 9, pp. 1745-1751, 2002.

[114] J.-F. Girmens, A. Erginay, P. Massin, P. Scigalla, A. Gaudric, and S. Richard, "Treatment of von Hippel-Lindau retinal hemangioblastoma by the vascular endothelial growth factor receptor inhibitor SU5416 is more effective for associated macular edema than for hemangioblastomas," American Journal of Ophthalmology, vol. 136, no. 1, pp. 194-196, 2003.

[115] S. Madhusudan, G. Deplanque, J. P. Braybrooke et al., "Antiangiogenic therapy for von Hippel-Lindau disease," Journal of the American Medical Association, vol. 291, no. 8, pp. 943-944, 2004.

[116] S. S. Dahr, M. Cusick, H. Rodriguez-Coleman et al., "Intravitreal anti-vascular endothelial growth factor therapy with pegaptanib 
for advanced von Hippel-Lindau disease of the retina," Retina, vol. 27, no. 2, pp. 150-158, 2007.

[117] J. Garcia-Arumí, L. H. Sararols, L. Cavero, F. Escalada, and B. F. Corcóstegui, "Therapeutic options for capillary papillary hemangiomas," Ophthalmology, vol. 107, no. 1, pp. 48-54, 2000.

[118] U. Schmidt-Erfurth, V. Chong, A. Loewenstein et al., "Guidelines for the management of neovascular age-related macular degeneration by the European Society of Retina Specialists (EURETINA)," British Journal of Ophthalmology, vol. 98, no. 9, pp. 1144-1167, 2014.

[119] M. Gharbiya, F. Parisi, F. Cruciani, F. Bozzoni-Pantaleoni, F. Pranno, and S. Abdolrahimzadeh, "Intravitreal anti-vascular endothelial growth factor for retinal angiomatous proliferation in treatment-naive eyes: long-term functional and anatomical results using a modified PrONTO-style regimen," Retina, vol. 34, no. 2, pp. 298-305, 2014.

[120] M. Gharbiya, F. Cruciani, F. Parisi, G. Cuozzo, S. Altimari, and S. Abdolrahimzadeh, "Long-term results of intravitreal bevacizumab for choroidal neovascularisation in pathological myopia," British Journal of Ophthalmology, vol. 96, no. 8, pp. 1068-1072, 2012.

[121] A. Lambiase, S. Abdolrahimzadeh, and S. M. Recupero, "An update on intravitreal implants in use for eye disorders," Drugs of Today, vol. 50, no. 3, pp. 239-249, 2014.

[122] V. Fenicia, S. Abdolrahimzadeh, G. Mannino, S. Verrilli, M. Balestrieri, and S. M. Recupero, "Intravitreal bevacizumab in the successful management of choroidal metastases secondary to lung and breast cancer unresponsive to systemic therapy: a case series," Eye, vol. 28, no. 7, pp. 888-891, 2014.

[123] S. Lazzeri, M. Figus, E. Di Bartolo, S. Rizzo, and M. Nardi, "Verteporfin photodynamic therapy for retinal hemangioblastoma associated with Von Hippel-Lindau disease in a 9-year-old child," Clinical and Experimental Ophthalmology, vol. 39, no. 2, pp. 179-181, 2011. 


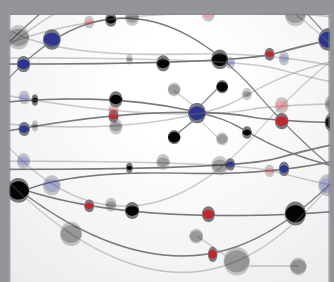

The Scientific World Journal
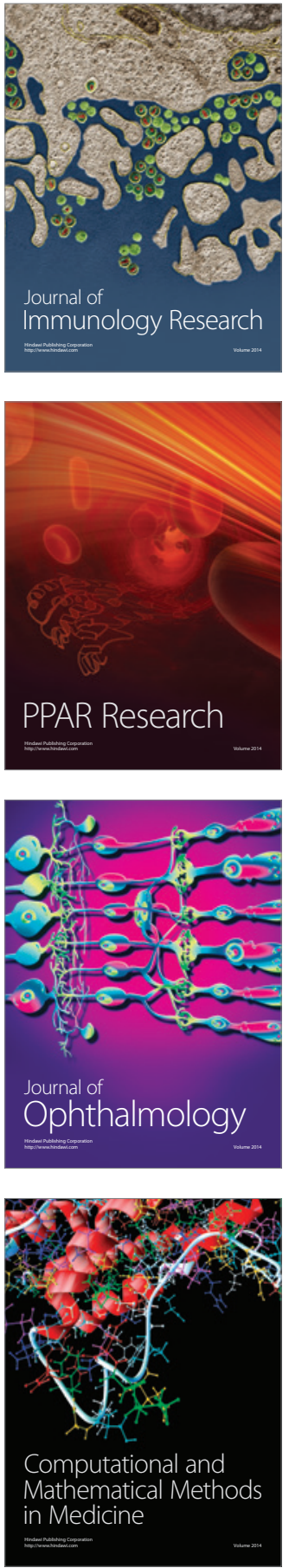

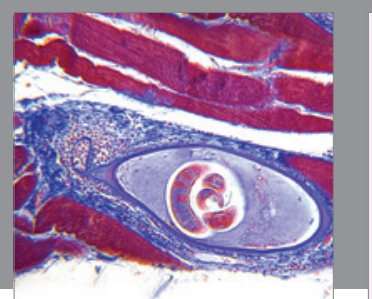

Gastroenterology Research and Practice

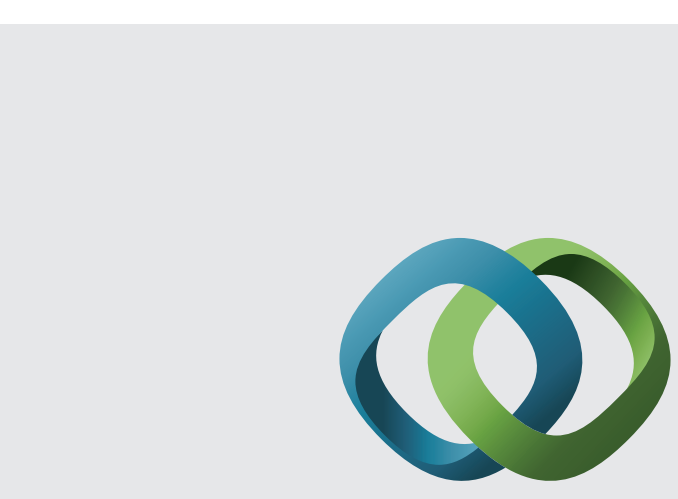

\section{Hindawi}

Submit your manuscripts at

http://www.hindawi.com
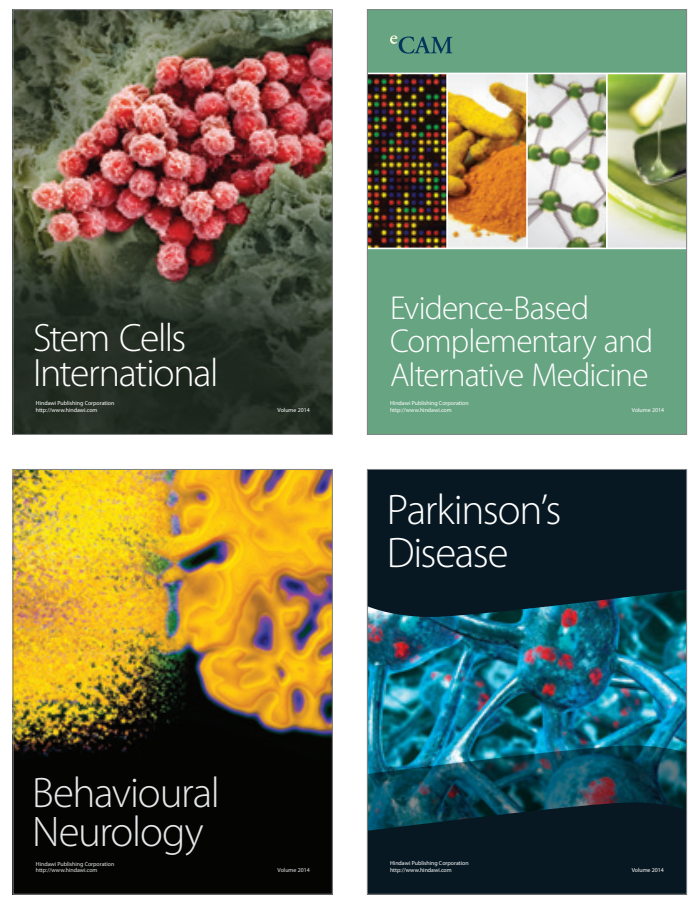
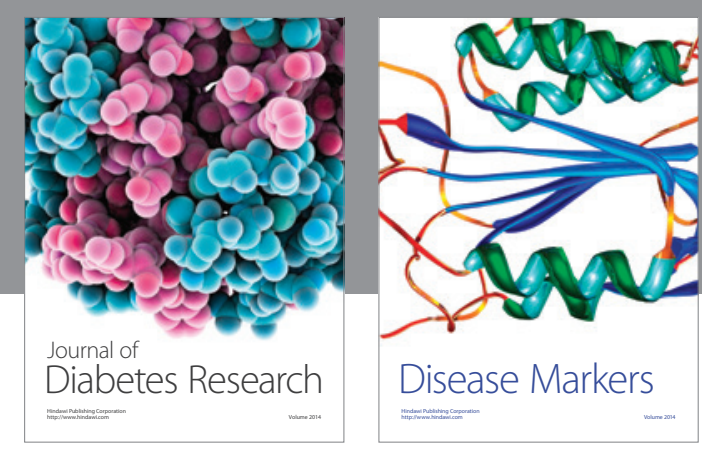

Disease Markers
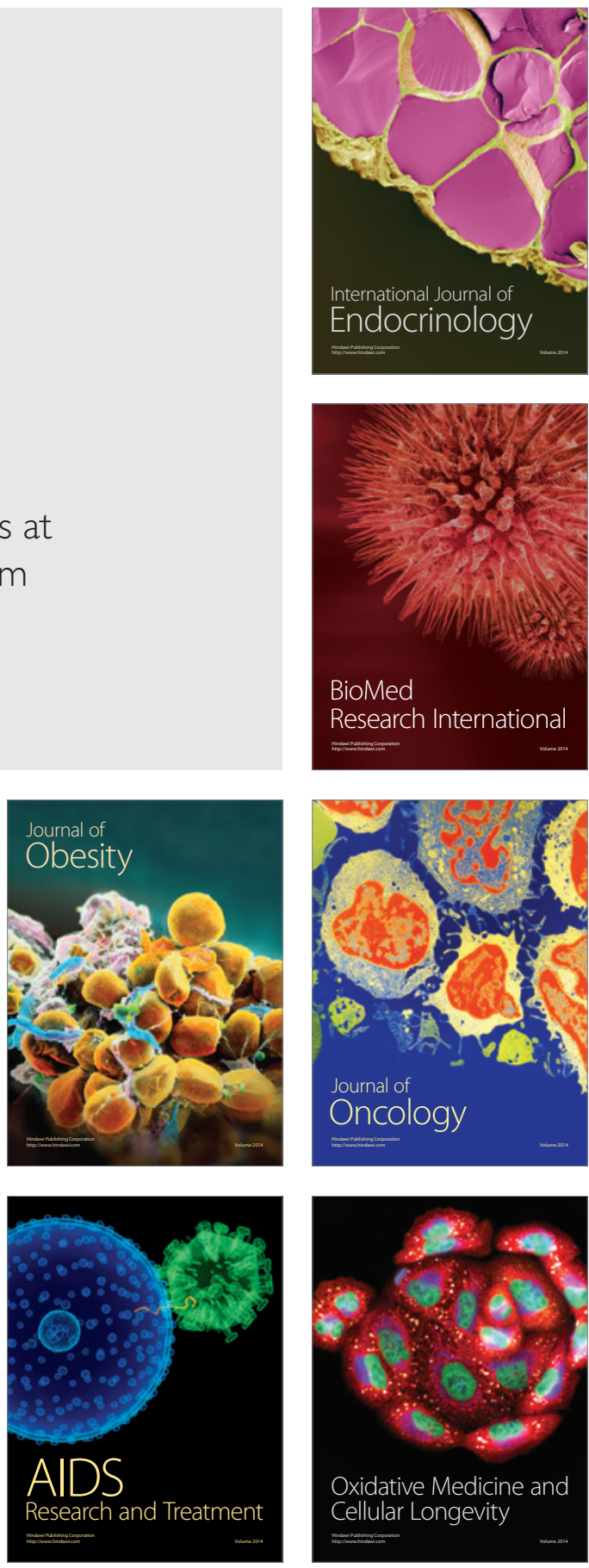